\title{
The Sorbus spp.- Underutilised Plants for Foods and Nutraceuticals: Review on Polyphenolic Phytochemicals and Antioxidant Potential
}

\author{
Viive Sarv ${ }^{1,2, *}$, Petras Rimantas Venskutonis ${ }^{1,3}$ (i) and Rajeev Bhat ${ }^{1}$ (I) \\ 1 ERA Chair for Food (By-) Products Valorisation Technologies of Estonian University of Life Sciences \\ -VALORTECH, Estonian University of Life Sciences, Fr. R. Kreutzwaldi 1a, 51014 Tartu, Estonia; \\ rimas.venskutonis@ktu.lt (P.R.V.); rajeev.bhat@emu.ee (R.B.) \\ 2 Institute of Agricultural and Environmental Sciences, Polli Horticultural Research Centre, 69108 Polli, Estonia \\ 3 Department of Food Science and Technology, Kaunas University of Technology, Radvilènu pl. 19, \\ LT-50254 Kaunas, Lithuania \\ * Correspondence: viive.sarv@emu.ee
}

Received: 25 July 2020; Accepted: 26 August 2020; Published: 1 September 2020

\begin{abstract}
The Sorbus spp. are valuable plants, which have been used for ornamental purposes, in traditional medicines and less seldom in foods. Recent studies have revealed different anatomical parts of the Sorbus spp. to contain valuable phytochemicals demonstrating various bioactivities. However, in terms of applications in the products intended for human consumption, Sorbus still remains as an underutilised genus. The increasing number of studies on phytochemicals, antioxidant potential and other bioactivities of Sorbus extracts has revealed the prospects of expanding its use in natural medicines, cosmetics and as innovative food ingredients, which might find wider applications in functional foods and/or nutraceuticals. Caffeoylquinic acids, flavonoids and proanthocyanidins have been reported in various Sorbus spp. as the most abundant polyphenolic antioxidants. The preparations of various plant anatomical parts have been used in ethnopharmacology as natural remedy for treating bacterial, viral, inflammatory diseases including tumors. Sorbus spp. plant parts have also been tested for management of diabetes, neurological, and cardiovascular disorders. The present review is focused on Sorbus plants (in total 27 Sorbus spp.), their composition and properties in terms of developing promising ingredients for foods, nutraceutical, cosmeceutical and other applications. It is expected that this review will assist in designing further studies of rowans and other Sorbus spp. in order to expand their uses for various human applications.
\end{abstract}

Keywords: rowan; phytochemical composition; bioactivities; health benefits; food applications

\section{Introduction}

During the past few decades, search and development for novel highly valued bioactive compounds from plants has become a topical issue for researchers, health professionals, producers, and consumers. Considering vast number of species in the Plant Kingdom, there are still infinite number of under explored plants, which may serve as an excellent platform for discovery of new compounds and developing valuable preparations. Underutilised plants have become of a particular interest in the era of functional foods, nutraceuticals and personalized nutrition. Thus, natural bioactive compounds can play the most important role in the development of health promoting products based on individual genome and/or microbiome [1,2].

Fruits and vegetables have been considered as healthy foods, mainly owed to the presence of high amounts of valuable nutrients such as vitamins, minerals, polyphenolic antioxidants, dietary fibre and others. In this regard, many well-known comprehensively valorised and globally commercialized 
berry fruits such as raspberries, strawberries, black currants, blueberries, cherries and others are among the richest sources of vitamins and bioactive phytochemicals, particularly antioxidant polyphenols. The above-mentioned berries also possess characteristic and highly appreciated sensory properties and hence are consumed both as fresh fruits and/or in processed forms. However, there are still many underutilised berries, mainly due to their specific and therefore non-acceptable for consumers flavour.

The Sorbus spp. (common names rowans, whitebeams and others) are deciduous shrubs or trees, which although being widely grown in the gardens and parks, can be assigned to the underutilized plants in terms of their applications as foods, nutraceuticals and/or cosmeceuticals. The rowans are the most widely studied Sorbus spp. Wild rowan trees are tolerant to harsh Nordic climate and poor growing environment such as rocky and windy slopes and even the mountains and may reach up to $15 \mathrm{~m}$ height.

Other anatomical parts of berry producing plants may also contain valuable phytochemicals; therefore, bark, leaves, inflorescences have been empirically used in folk medicines for centuries. The bark of the Sorbus trees is mostly smooth, lustrous, dark, with elongated horizontal lenticels; the leaves are pinnately compound, the leaflets toothed or rarely entire, while the inflorescences may be extra-large, convex panicles [3]. The interest in Sorbus spp. as a promising source of valuable phytochemicals has increased during last decade. For instance, in the Clavirate Analytics Web of Science database, out of 133 publications with the search words 'Sorbus + antioxidants' 105 have been included since 2010; while in the same period 68 records out of 91 have been found with the search words 'Sorbus + polyphenolics' (accessed on 20 July 2020). Comprehensive review on Sorbus phytochemicals has been recently published; it focuses on Sorbus as an ethnopharmacologically important but underestimated genus and provides extensive information on plant phytochemicals [4]. The present review focuses on Sorbus composition and properties in terms of development of promising ingredients for food, nutraceutical, cosmeceutical and other applications. For this purpose, it includes some important information; for instance, more detailed data on until now reported concentrations of different polyphenolic phytochemicals and the values of antioxidant potential in different Sorbus spp. This information might assist in selecting the most promising species/cultivars and their anatomical parts for further studies and applications.

\section{Botanical Classification and General Uses}

The copious genus Sorbus L. (Rosaceae, Maloideae) covers up to 250 species, which in addition are divided into 6 subgenus, namely Sorbus, Aria, Micromeles, Cormus, Tominaria, and Chamaemespilus. According to Robertson et al. [3] approximately 35 species exist in the Caucasus and Turkey, 91 in Europe, and 111 in China, Vietnam, Myanmar, and in the Himalayas. The bitter fruits of wild rowan are round in shape and they can be red, orange, yellow, pink or white with homogeneous flesh (Figure 1) [3]. The rowan tree can yield up to $20 \mathrm{~kg}$ of rowanberries [5]. Traditionally, people consumed rowanberries in small amounts as a mash to improve the appetite and stimulate production of gastric acid. In folk medicine these fruits have been used as a laxative, against rheumatism and kidney diseases, and gargle juice against hoarseness [6]. Rowan berries have been traditional diuretic, vasodilatory, anti-inflammatory, anti-diarrheal remedies and a source of ascorbic acid (vitamin C); in some countries they also have been used for treating intestinal obstructions, various liver and gallbladder diseases [7]. The leaves have sometimes been used to feed livestock while the fruits have been administered to domestic pigs and goats against bacterial infections [8]. In order to make the selection of abundant genus Sorbus the species listed in the United States Department of Agriculture (USDA) database [9] were used in the current review. In addition, the species with a more comprehensively investigated bioactivity were included. 


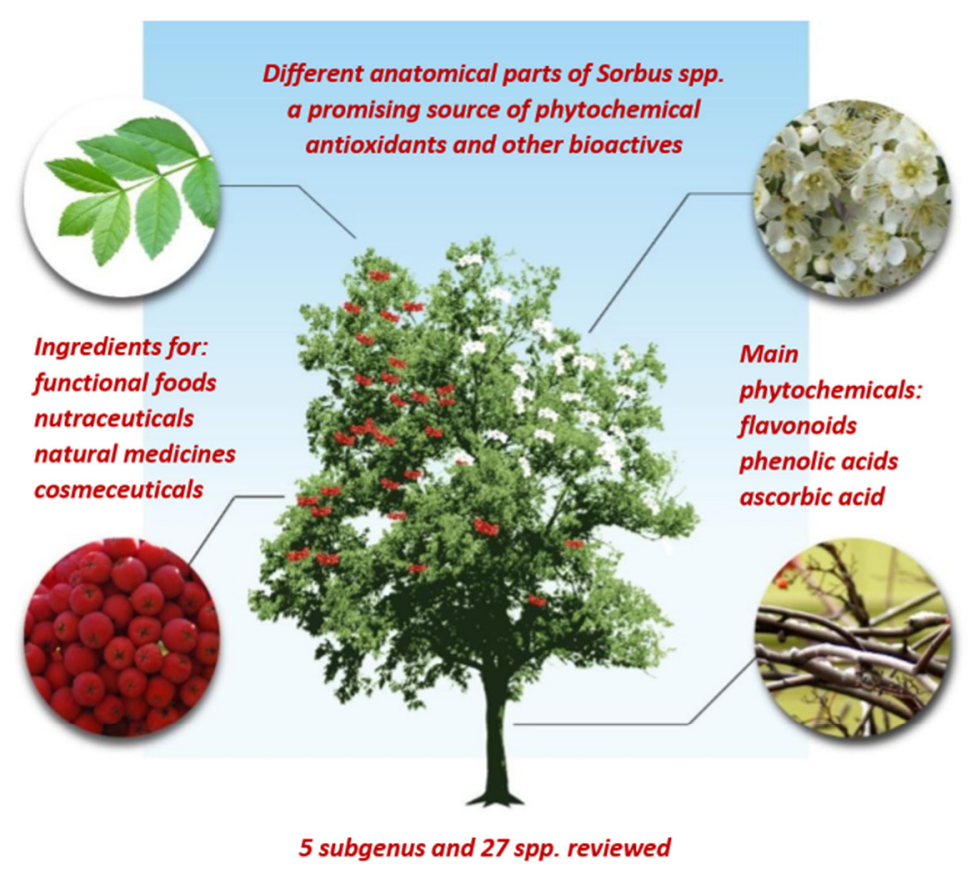

Figure 1. Potential uses of different parts of Sorbus spp.

The subgenus Sorbus, commonly noted as a mountain ash (Amur or European mountain ash), rowan or quick beam, is distributed in the Northern Hemisphere. It has hairless or thinly hairy leaves [3]. This review covers 19 species from the large Sorbus subgenus (Table 1): S. americana Marshall (American mountain ash), S. aucuparia, S. californica Greene (California mountain ash), S. cashmiriana Hedl., S. commixta Hedl. (The Japanese rowan), S. decora C.K. Schneid, (the northern mountain ash), S. dumosa Greene (Arizona Mountain Ash), S. gracilis (Sieb. \& Zucc.) K. Koch., S. groenlandica (C.K. Schneid.) A. Löve \& D. Löve (the Greenland mountain-ash), S. koehneana C.K. Schneid. (Koehne mountain ash), S. pohuashanensis (Hance) Hedl., S. pogonopetala Koehne, S. sambucifolia (Cham. \& Schlecht.) Roem. (Siberian Mountain-ash), S. scalaris Koehne, S. scopulina Greene, S. setschwanensis (C.K. Schneid.) Koehne, S. sitchensis M. Roem (western mountain ash), S. tianschanica Rupr., S. wilfordii Koehne. Different anatomical parts of these species have been used for medicinal and food purposes (Figure 1). The leaves of $S$. tianschanica have been used to treat asthma, ventricular myocytes, dyspnoea, tuberculosis and gastritis [10], while both the leaves and the bark of $S$. decora are known as an antidiabetic medicine [11]. The bark of S. americana, due to hypo-glycaemic properties has also been used for treating diabetes; while other applications include vaso-relaxant, antitussive and tonic activities [12]. In oriental medicine, the stems and bark of S. commixta have been used to treat arthritis and inflammatory diseases and as hypoglycaemic, vasorelaxant, antitussive and tonic agents $[13,14]$. The bark preparation of S. cashmiriana has been used to treat nausea and heart diseases, while its berries have been used to cure scurvy [15]. The fruits, stems and bark S. pohuashanensis have been widely used in traditional Chinese medicine for treating chronic tracheitis, tuberculosis and oedema [16]. The fruits of S. sambucifolia have been used in drinks and foods (beverages, jams, jellies, floured dried fruit, etc.), while for medicinal purposes-in case of avitaminosis, arteriosclerosis and as antipyretic or diuretic agent. Indigenous people used to eat fresh S. scopulina berries; however, currently they are sometimes used in pies, preserves, or wine-making [17]. In folk medicine, the fruits and the inflorescences of $S$. aucuparia (European rowan) have been used as traditional anti-inflammatory, antidiarrheal, vasodilatory and an appetite-improving agents, as well as a good source of vitamins, diuretic and mild laxative medicine [18,19]. In traditional Austrian medicine, the tea, syrup, jelly or alcoholic tincture of $S$. aucuparia fruits have been used to treat fever, infections, colds, flu, rheumatism and gout [20]. 
From the subgenus Aria with 39 species, commonly known as whitebeams, 6 species, namely S. aria Crantz, S. intermedia (Ehrh.) Pers., S. norvegica Hedl., S. folgneri (Schneid.) Rehd., S latifolia (Lam.) Pers, and S. minima (Ley) Hedl. are covered in this review. These species have simple white-hairy leaves and are distributed in the temperate regions of Europe and in Asia. Traditionally, the leaves of S. aria were consumed as antidiarrheal ingredients, while their berries have been used in jellies, jams, brandy, liqueurs, conserves and vinegar, as traditional bread flour extender, diuretic, anti-inflammatory, anti-diarrhoeal, vasodilatory agent and vitamin source [21]. Moreover, the fruits and inflorescences of $S$. aria have been used as a diuretic, laxative and emmenagogue folk medicine for treating painful menstruation, constipation and kidney disorders [22]. The berries of S. intermedia have been added to bread in Estonia [23], while the berries of S. norvegica, S. folgneri, S latifolia and S. minima were tested for their $\alpha$-amylase and $\alpha$-glucosidase inhibitory activities [24].

The subgenus Micromeles, commonly known as Korean whitebeam, alder-leafed whitebeam, contains around 25 narrow leaved species of shrubs and trees with white flowers, distributed from Nepal to the South Kuriles, extending to the Malay Peninsula and Sumatra [25]. In the Korean folk medicine the twigs of the most widely distributed species, S. alnifolia (Siebold \& Zucc.) K. Koch., were used for treating neurological disorders [26].

Aria, Micromeles and Chamaemespilus have simple leaves and pomes with groups of tanniferous cells, however, Chamaemespilus (false medlar or dwarf whitebeam) differs by a rather different flower shape [27]. Chamaemespilus is not reviewed in the current study due to the lack of information about its uses and antioxidant activity.

The subgenus Torminaria (common names wild service tree, chequers, and checker tree) with three species is distributed in the temperate Europe, south to the mountains of North Africa and east to the Caucasus ranges. It has maple-like simple, 3-5-lobed leaves and brown pomes without groups of tanniferous cells. The fruits of $S$. torminalis have been traditionally used as diuretic or anti-inflammatory, antidiarrheal (dried), vasodilatory remedy and as a source of vitamins [27,28]. In the current work, the uses and antioxidant potential of 2 varieties of $S$. torminalis, (var. torminalis and semitorminalis) are surveyed.

The subgenus Cormus with pomes without starch and groups of tanniferous cells [27] and compound leaves, is distributed in the warm-temperate Europe, North Africa and Asia. Unlike the subgenus Sorbus, Aria and Torminaria, whose fruit carpels are not fused, subgenus Cormus is with distinct fused carpels in the fruit. In this review only $S$. domestica, also known as true service tree or sorb tree [29], is included. It has been reported that the fruits of S. domestica are traditional anti-inflammatory, antidiarrheal (dried), antidiabetic, diuretic, vasodilatory agents and vitamin source [30].

Although, wild rowanberries are sour in taste they still contain a wide array of healthy components. In the beginning of the 20th century, the Russian practitioner Michurin started the breeding program with $S$. aucuparia to improve the flavour and increase the fruit mass of rowanberries. Crossbreeding of rowan with the Malus, Mespilus, Aronia, or Pyrus spp. produced interesting sweet-fruited rowan hybrids. These new hybrids have been bred particularly for northern conditions and they have demonstrated great frost-resistance in the Nordic countries [31]. The famous crossbreeds of S. aucuparia in Russia were called 'Burka', 'Likjornaja', 'Dessertnaja', 'Granatnaja', 'Rubinovaja', and 'Titan' [32]. The Western European hybrids of S. aucuparia include 'Apricot Queen', 'Brilliant Yellow', 'Chamois Glow', 'Pink Queen', and 'Salmon Queen' [33]. In contrast to wild rowanberries, the hybrids are much more palatable [34] and the sugar content in their cultivars is 1.2-2.1 times higher than in the wild rowanberries [35]. In the current review, the bioactivity and phytochemical contents of several S. aucuparia cultivars are compared with the wild berries. 
Table 1. Botanical classification of selected Sorbus spp. and their uses.

\begin{tabular}{|c|c|c|c|}
\hline Species and Varieties (Subgenus) & Food Uses of Fruits & Anatomical Part: Medicinal and Other Uses & Ref. \\
\hline S. alnifolia (Sieb. \& Zucc.) K. Koch. (Aria) & & $\begin{array}{l}\text { Twigs: treatment of neurological disorders as a } \\
\text { traditional medicine in Korea }\end{array}$ & [26] \\
\hline $\begin{array}{c}\text { S. americana Marshall- } \\
\text { American mountain ash (Sorbus; informal } \\
\text { group Commixtae) }\end{array}$ & & $\begin{array}{l}\text { Bark: treatment diabetes hypo-glycaemic, } \\
\text { vaso-relaxant, antitussive and tonic agent }\end{array}$ & [36] \\
\hline S. aria L. Crantz-chess-apple (Aria) & $\begin{array}{l}\text { Jellies, jams, brandy, liqueurs, } \\
\text { conserves and vinegar, } \\
\text { traditional bread } \\
\text { flour extender }\end{array}$ & $\begin{array}{l}\text { Fruit: diuretic, anti-inflammatory, anti-diarrhoeal, } \\
\text { vasodilatory and vitamin agent; leaves: } \\
\text { ethnomedical antidiarrheal ingredients; } \\
\text { inflorescences and fruit: diuretic, laxative and } \\
\text { emmenagogue; treatment of painful menstruation, } \\
\text { constipation and kidney disorders }\end{array}$ & $\begin{array}{l}{[11]} \\
{[18]} \\
{[37]}\end{array}$ \\
\hline S. aucuparia L.—European mountain ash (Sorbus) & $\begin{array}{l}\text { Alcohol beverages, jams, } \\
\text { jellies, honey (floured } \\
\text { dried fruit) }\end{array}$ & $\begin{array}{l}\text { Traditional diuretic, anti-inflammatory, antidiarrheal } \\
\text { (dried fruits), vasodilatory and an appetite- } \\
\text { improving agent, source of vitamins, mild laxative }\end{array}$ & $\begin{array}{c}{[18]} \\
{[22]} \\
{[7]}\end{array}$ \\
\hline S. cashmiriana Hedl. (Sorbus series Multijugae) & & $\begin{array}{c}\text { Bark: tea made from its bark-to treat nausea, the } \\
\text { bark preparation- to treat heart diseases; berries: to } \\
\text { cure scurvy }\end{array}$ & [15] \\
\hline S. commixta Hedl. (Sorbus; informal group Commixtae) & & $\begin{array}{l}\text { Stembark: for treating asthma, bronchitis, gastritis } \\
\text { and oedema, anti-inflammatory, -atherosclerotic, } \\
\text {-alcoholic, and vascular-relaxant effects, } \\
\text { anti-atherogenic, for treating arthritis, } \\
\text { hypoglycaemic, antitussive and tonic agent }\end{array}$ & $\begin{array}{l}{[38]} \\
{[14]} \\
{[39]} \\
{[13]}\end{array}$ \\
\hline $\begin{array}{l}\text { S. decora (Sarg.) C.K. Schneid-northern mountain } \\
\text { ash (Sorbus; informal group Commixtae) }\end{array}$ & & Leaves and bark- an antidiabetic medicine & [11] \\
\hline S. domestica L. (Cormus) & Food ingredients & $\begin{array}{c}\text { Traditional diuretic, anti-inflammatory, antidiarrheal } \\
\text { (dried fruits), vasodilatory, antidiabetic and } \\
\text { vitamin agents }\end{array}$ & $\begin{array}{l}{[18]} \\
{[40]} \\
{[41]}\end{array}$ \\
\hline $\begin{array}{l}\text { S. hybrida L.—oakleaf mountain ash (Aria sect. } \\
\text { Aria } \times \text { Sorbus) }\end{array}$ & & An ornamental tree in northern Europe & [42] \\
\hline S. pohuashanensis (Hance) Hedl. (Sorbus) & & $\begin{array}{l}\text { Fruits, stems and bark: traditional Chinese medicine } \\
\text { for the treatment of chronic tracheitis, tuberculosis } \\
\text { and oedema }\end{array}$ & [16] \\
\hline $\begin{array}{l}\text { S. sambucifolia (Cham. \& Schlecht.) M. } \\
\text { Roem.-Siberian mountain ash (Sorbus } \\
\text { Lucidae Kom.) }\end{array}$ & $\begin{array}{l}\text { Alcohol beverages, jams, } \\
\text { jellies, honey (floured } \\
\text { dried fruit) }\end{array}$ & $\begin{array}{c}\text { In avitaminosis, arteriosclerosis, as antipyretic or } \\
\text { diuretic agent. }\end{array}$ & [43] \\
\hline $\begin{array}{l}\text { S. scopulina Greene-Greene's mountain ash (Sorbus; } \\
\text { informal group Commixtae) }\end{array}$ & $\begin{array}{l}\text { Sometimes used in pies, } \\
\text { preserves, or wine-making }\end{array}$ & & [17] \\
\hline $\begin{array}{c}\text { Sorbus } \times \text { thuringiaca } \text { (Ilse) Fritsch-mountain ash } \\
(\text { Aria sect. Aria } \times \text { Sorbus })\end{array}$ & & An ornamental tree & [44] \\
\hline $\begin{array}{l}\text { S. tianschanica Rupr. (Sorbus series } \\
\text { Tianshanicae Kom.) }\end{array}$ & & $\begin{array}{l}\text { Leaves: asthma, ventricular myocytes, dyspnoea, } \\
\text { tuberculosis and gastritis }\end{array}$ & [10] \\
\hline S. torminalis (L.) Crantz var. torminalis (Torminaria) & $\begin{array}{l}\text { Jams and ingredients for food } \\
\text { and fodder }\end{array}$ & $\begin{array}{l}\text { Traditional diuretic, anti-inflammatory, antidiarrheal } \\
\text { (dried fruits), vasodilatory and vitamin agents }\end{array}$ & $\begin{array}{l}{[18]} \\
{[28]} \\
{[40]}\end{array}$ \\
\hline S. torminalis var. semitorminalis (Torminaria) & & $\begin{array}{l}\text { Traditional diuretic, anti-inflammatory, antidiarrheal } \\
\text { (dried fruits), vasodilatory and vitamin agents }\end{array}$ & [18] \\
\hline
\end{tabular}

\section{Nutritional Composition}

Wild rowanberries are not consumed as fresh fruits due to their specific astringent taste, imparted mainly by the tannins. These cause the dry feeling in the mouth when consumed. Therefore, they have rather limited applications for producing food products. However, due to the nutritive value and health benefits the berries of S. aria, S. aucuparia, S. domestica, S. sambucifolia, S. scopulina, and S. torminalis have been traditionally used for pressing juice, in alcoholic beverages, purees, jams and jellies $[28,35]$. These benefits are due to the significant amounts of phytochemicals, such as vitamins, carotenoids, and phenolic acids as well as important in nutrition minerals, iron, potassium, and magnesium. In addition, rowanberries contain a sweet-tasting sugar alcohol sorbitol, which slowly metabolizes in the human body and therefore is suitable as a sweetener for people suffering from diabetes [45].

It was reported that rowanberries contain 3-fold higher amount of ascorbic acid than oranges [5]. For instance, Mrkonjić et al. [28] determined approximately $0.1 \mathrm{mg} / \mathrm{g}$ d.w. (dry weight) of ascorbic acid in S. aucuparia berries and $0.42 \mathrm{mg} / \mathrm{g} \mathrm{dw}$ in fruit jam. The recommended dietary allowance of ascorbic acid is $60 \mathrm{mg}$ per day, while $5-7 \mathrm{mg}$ a day prevents scurvy. Tocopherols are important fat-soluble vitamins in rowanberries. The mean concentrations of vitamin $\mathrm{E}$ activity demonstrating $\alpha$-tocopherol, $\delta$-tocopherol, and $\gamma$-tocopherol in S. aria and S. aucuparia were reported $2.82,0.11,2.01 \mu \mathrm{g} / \mathrm{g} \mathrm{dw}$ 
and $4.89,0.58,1.71 \mu \mathrm{g} / \mathrm{g} \mathrm{dw}$, respectively [46]. Klavins et al. [47] determined even higher content of $\alpha$-tocopherol $(3.34 \mu \mathrm{g} / \mathrm{g} \mathrm{dw})$ in S. aucuparia fruit, while the content of $\gamma$-tocopherol was remarkably lower, $0.25 \mu \mathrm{g} / \mathrm{g} \mathrm{dw}$. The recommended intake of vitamin $\mathrm{E}$ for adults is in the range of 7 to $15 \mathrm{mg}$ per day. The epidemiological studies showed that humans who consumed vitamin E richer foods had lower incidence of cancer, dementia and/or cardiovascular diseases [48].

In nature, $\beta$-carotene, a precursor (inactive form) of vitamin $A$, is a strongly coloured red-orange pigment, which is abundant in some plants and fruits. Berna and Kampuse reported that S. aucuparia contains $2.5 \mathrm{mg}$ of total carotenoids per $100 \mathrm{~g}$ [49]. The average daily intake of the strong antioxidant $\beta$-carotene is in the range of $2-7 \mathrm{mg}$, as estimated from a pooled analysis of 500,000 women living in the US, Canada, and some European countries [50]

The minerals are important for all living organisms. Aslantas et al. reported high content of 8 essential minerals in S. aucuparia (in $\mathrm{mg} / 100 \mathrm{~g}$ ): potassium, 154; phosphorus, 12.3 ; calcium, 29.9; magnesium, 27.84; iron, 2.42; copper, 0.294; zinc, 0.861; and manganese 0.503 [51]. The tree bark of S. domestica has been reported as a good source of $\mathrm{Ca}, \mathrm{Zn}, \mathrm{Fe}$, while the seeds were rich in $\mathrm{K}, \mathrm{Mg}$, $\mathrm{Fe}$ and $\mathrm{Zn}$ [30]. Plant oils are important as food ingredients and as a source of essential fatty acids for human nutrition. In seed oils of S. aucuparia the sum of linoleic and oleic acids exceeded $90 \%$ of the total fatty acids [37]. Ivakhnov et al. [52] optimized the procedure for oil extraction from S. aucuparia alcoholic beverage production waste using the supercritical $\mathrm{CO}_{2}$ as a solvent and recovered $9.02 \%$ $(\mathrm{w} / \mathrm{w})$ high quality oil.

\section{Total Phenolic Content and Quantitative Composition of Phytochemical Antioxidants in Sorbus spp.}

\subsection{Total Phenolic Content}

In general, the leaves and inflorescences of Sorbus spp. were reported to contain higher amounts of the total phenolic content (TPC) than the fruits (Table 2). Usually TPC is expressed in gallic acid equivalents (GAE). Thus, the highest TPC was reported in the dried leaves of $S$. wilfordii (12.31\% GAE), as well as in the inflorescences of S. aucuparia (11.83\% GAE) [53]. Predominantly, in the tested plant parts of the Sorbus spp., the total level of phenolics was significantly higher in the inflorescences than in the leaves [54], except for S. gracilis, when the TPC in the leaves was slightly higher than in the inflorescences, 11.06 and $10.72 \%$ GAE, respectively [53]. The highest TPC in fruit was detected in S. aria $(2.98 \% \mathrm{GAE}) \mathrm{dw}$; the fruits of S. aucuparia and S. intermedia contained only slightly lower TPC, $2.68 \%$ and $2.24 \% \mathrm{GAE} \mathrm{dw}$, respectively [54]. The lowest TPC values among the tested Sorbus spp. was found in the S. americana fruits; it was only $3.60-5.39 \mathrm{mg} / \mathrm{g} \mathrm{dw}[54,55]$. Gaivelyte et al. analysed leaf and fruit material of 10 Sorbus spp. and 9 cultivars and found that the TPC varied approximately 5 times, both in leaf and fruit samples, i.e., in the range of $7.18-35.74 \mathrm{mg} / \mathrm{g}$ and $2.24-11.19 \mathrm{mg} / \mathrm{g}$, respectively [56]. The berries of S. aria and S. aucuparia grown at different altitudes were compared; however, there was no correlation between TPC, total proanthocyanidins, radical scavenging capacity and growing site. Nevertheless, slightly higher TPC values were observed in S. aucuparia, while S. aria had higher content of proanthocyanidins [57].

TPC may highly depend on berry maturity, while the recovery of phenolics depends on extraction solvent. For instance, the diethyl ether fraction separated from the crude methanol extract isolated from fruit pulp of $S$. domestica berries matured at room temperature for 1 week had the highest TPC [58]. Bobinaite et al. [59] reported the TPC in acetone, ethanol and water extracts of rowanberry pomace, which was almost similar, 10.94, 10.43 and $9.60 \mathrm{mg} / \mathrm{g}$, respectively; while the content of individual compounds depended remarkably on the applied solvent. It was suggested that considering only slight differences in the recovery of total phenolics between the applied solvents, water would be the most attractive due to the price, availability and safety.

Olszewska et al. [37] investigated the effects of extraction with chloroform and $70 \%$ methanol and fractionation with diethyl ether, ethyl acetate, $n$-butanol of soluble in different solvents substances present in inflorescences and leaves of 7 Sorbus spp., namely S. aucuparia, S. commixta, S. decora, 
S. gracilis, S. koehneana, S. pogonopetala and S. wilfordii. N-butanol and ethyl acetate were the most effective in recovering antioxidants from Sorbus leaves, whereas ethyl acetate, $n$-butanol and diethyl ether fractions of S. pogonopetala and S. wilfordii leaves contained the highest TPC, 39.56-58.17\% dwe (dry weight of extract).

\subsection{Phenolic Acids}

Chlorogenic (3-O-caffeoylquinic acid, 3-CQA) and neochlorogenic acids (5-O-caffeoylquinic acid, 5-CQA) are the main phenolic acids reported in Sorbus spp. [53,55,57]. Moreover, it has been reported that caffeoylquinic acids constitute $56-80 \%$ of the total phenolics in Sorbus fruits, whereas the cultivated berries contain less caffeoylquinic acids than wild rowanberries [60]. The content of chlorogenic acid in the berries of S. aucuparia was up to $10.01 \mathrm{mg} / \mathrm{g} \mathrm{dw}$ [57], while the content of neochlorogenic acid in the tested 5 cultivars was up to $7.31 \mathrm{mg} / \mathrm{g} \mathrm{dw}$ [60]. Generally, the content of caffeoylquinic acids in the inflorescences was reported to be higher than in the leaves or berries. The predominant caffeoylquinic acid in the all assayed inflorescence samples was chlorogenic acid [54-57,60] with the highest concentration in S. sambucifolia, $4.17 \% \mathrm{dw}$ [53] the highest contents of neochlorogenic acid were in the inflorescences of S. koehneana (1.98\%), S. decora (1.26\%) [53], and S. aucuparia (1.37\%) [54]. The concentrations of chlorogenic acid in water and methanol extracts, as well as in the jam of S. aucuparia were $5.69,5.80$ and $2.60 \mathrm{mg} / \mathrm{g} \mathrm{dw}$, respectively [28]. It seems that some species instead of chlorogenic acids biosynthesize ferulic acid as the major one; in the methanol and water extracts and jams of S. torminalis its content was up to $62.6 \mu \mathrm{g} / \mathrm{g} \mathrm{dw}$ [28].

In addition, ferulic acid content was reported in the leaves of some Sorbus spp., such as S. aucuparia, S. aria [43] and S. subfusca [61]. The methanol and water extracts and jams of both $S$. torminalis var. torminalis and semitorminalis also contained up to $23.2 \mu \mathrm{g} / \mathrm{g} \mathrm{dw}$ protocatechuic acid, while in the jam of S. aucuparia its concentration was $12.5 \mu \mathrm{g} / \mathrm{g} \mathrm{dw}$. Protocatechuic acid was also reported in the fruits, leaves and bark of S. alnifolia [62], in the extracts of S. aucuparia, S. commixta, S. gracilis, S. decora and S. koehneana inflorescences [37], in the extracts of S. gracilis, S. pogonopetala, S. wilfordii [37], S. domestica leaves [63] and in the S. domestica fruit pulp [41]. Gallic acid was found only in the water extract of S. torminalis var. semitorminalis in concentration of $5.69 \mu \mathrm{g} / \mathrm{g} \mathrm{dw}$ [28].

Some other well-known phenolic acids and their derivatives such as cinnamic, vanillic, $p$-coumaric and benzoic acids have been found in traces in the fruits of S. aucuparia [64] and S. domestica [41], while $p$-coumaric acid was also detected in the $S$. discolor berries [40]. Caffeic acid and its derivatives were reported in the berries of S. aucuparia [40], S. domestica [62], S. discolor [40], S. alnifolia [62], S. pohuashanensis [16], S. torminalis [40]. Vanillic acid was found in the leaves of S. aria [40], coumaric acid in the inflorescences of S. aucuparia, S. commixta, S. decora, S. gracilis, S. koehneana and in the leaves of S. domestica [63], S. pogonopetala, S. gracilis, and S. wilfordii [37].

\subsection{Flavonoids}

Quercetin, kaempferol, isoquercetin, rutin, hyperoside and isorhamnetin were reported in the samples of selected Sorbus fruits, leaves and inflorescences as the major flavonoids (Figure 2). Quercetin was the predominant flavonoid in all selected leaf and inflorescence samples and the highest values were found in the inflorescences of S. aucuparia $(1.11 \% \mathrm{dw})$ followed by S. intermedia $(1.05 \% \mathrm{dw})$ [18]. Among the leaf samples the highest content of quercetin was determined in S. aucuparia and S. wilfordii, $0.88 \%$ and $0.90 \% \mathrm{dw}$, respectively [53]. The content of quercetin in the fruits of S. aucuparia, S. intermedia, S. aria was $0.51,0.31,0.09 \mathrm{mg} / \mathrm{g}$, respectively [54]. The highest content of isoquercetin was found in $S$. commixta fruits and leaves, $0.65 \mathrm{mg} / \mathrm{g}$ and $5.24 \mathrm{mg} / \mathrm{g}$, respectively; among analysed rowanberries, the fruits of the same species had the highest content of hyperoside, $1.19 \mathrm{mg} / \mathrm{g}$ [56]. Kaempferol was quantified in the fruits, leaves and inflorescences of S. aria, S. aucuparia and S. intermedia; the highest content of this flavonoid was present in S. aucuparia [54]. The leaves of S. setschwanensis and S. aria were also rich in kaempferol, which constituted $0.31 \%$ [53] and $0.26 \% \mathrm{dw}$ [54], respectively. Isorhamnetin was found only in the 
fruits [40], leaves and inflorescences of S. torminalis [28], S. intermedia and S. aria [54]. Some isorhamnetin conjugates were also identified in S. discolor [40] and S. domestica [18]. Olszewska et al. using bioactivity-guided assay isolated several flavonoids, such as isorhamnetin $3-O-\beta$-glucopyranoside, astragalin, isoquercitrin, hyperoside, kaempferol 3-O- $\beta$-glucopyranoside-7-O- $\alpha$-rhamnopyranoside, quercetin 3-O- $\beta$-glucopyranoside-7-O- $\alpha$-rhamnopyranoside, rutin, from the leaves of $S$. aria [65]. Among 10 investigated fruit samples of $S$. aria and S. aucuparia the highest content of rutin was found in the S. aria fruits reaching up to $892 \mu \mathrm{g} / \mathrm{g} \mathrm{dw}$ [57]. Rutin was also abundant in the leaves of S. anglica [56].<smiles>COc1cc(-c2oc3cc(O)cc(O)c3c(=O)c2O)ccc1O</smiles>

Isorhamnetin<smiles></smiles>

Hyperoside

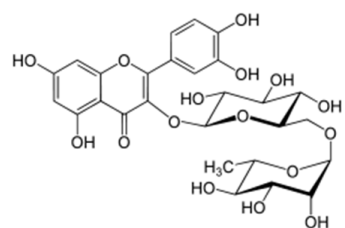

Rutin

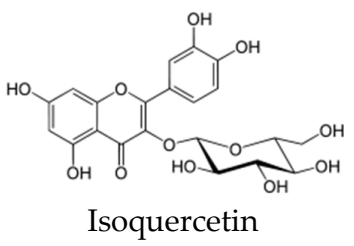

Isoquercetin

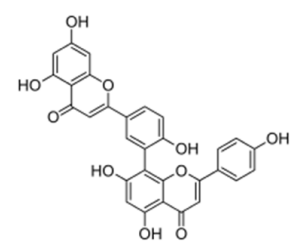

Amentoflavone

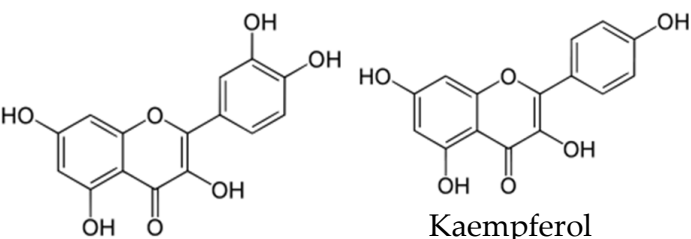

Quercetin<smiles>COc1c(O)cc(O)c2c(=O)c(O)c(-c3ccc(O)cc3)oc12</smiles>

Sexangularetin

Figure 2. The structures of the main Sorbus flavonoids.

Table 2. Bioactive compounds in selected Sorbus species.

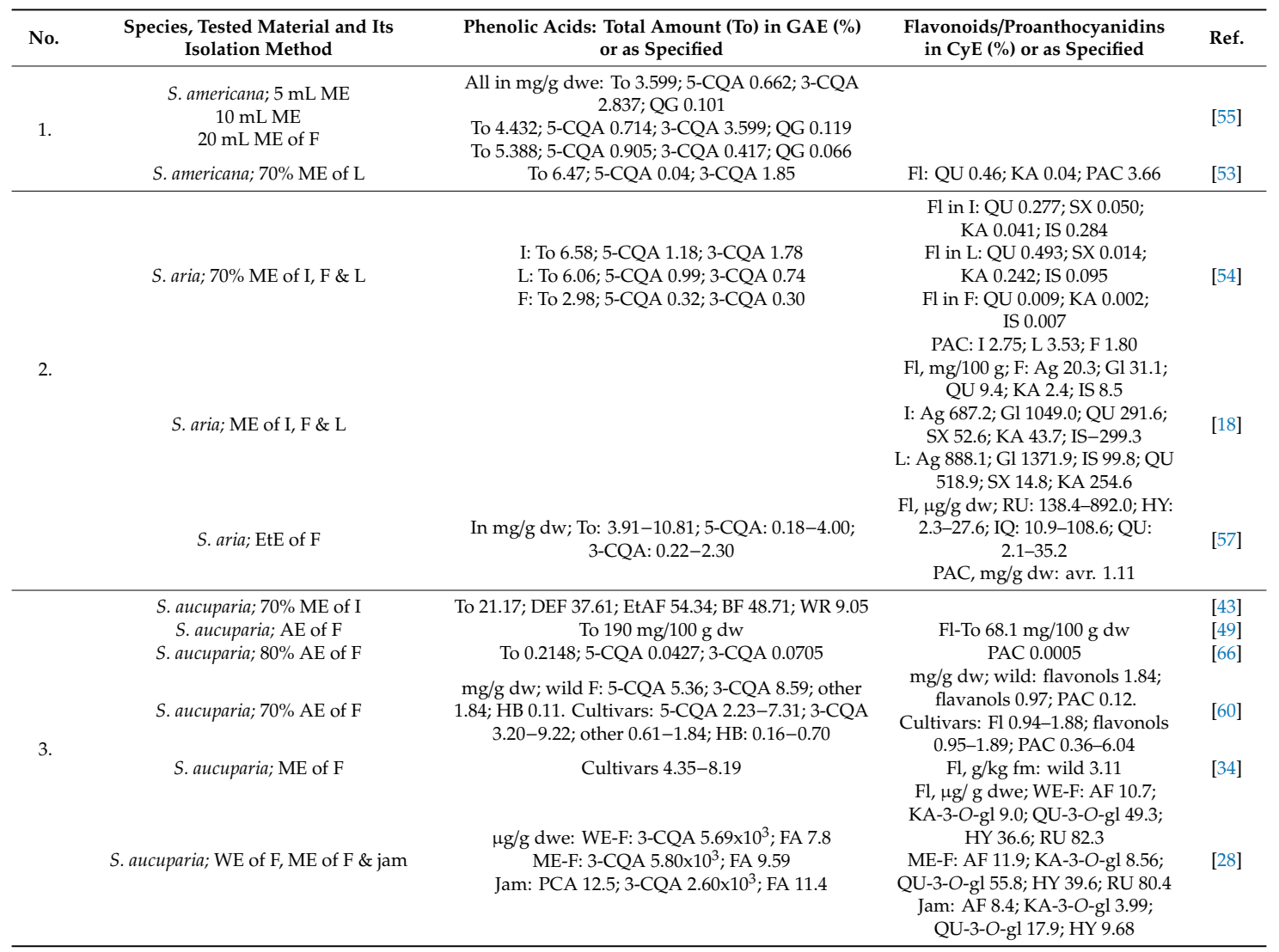


Table 2. Cont.

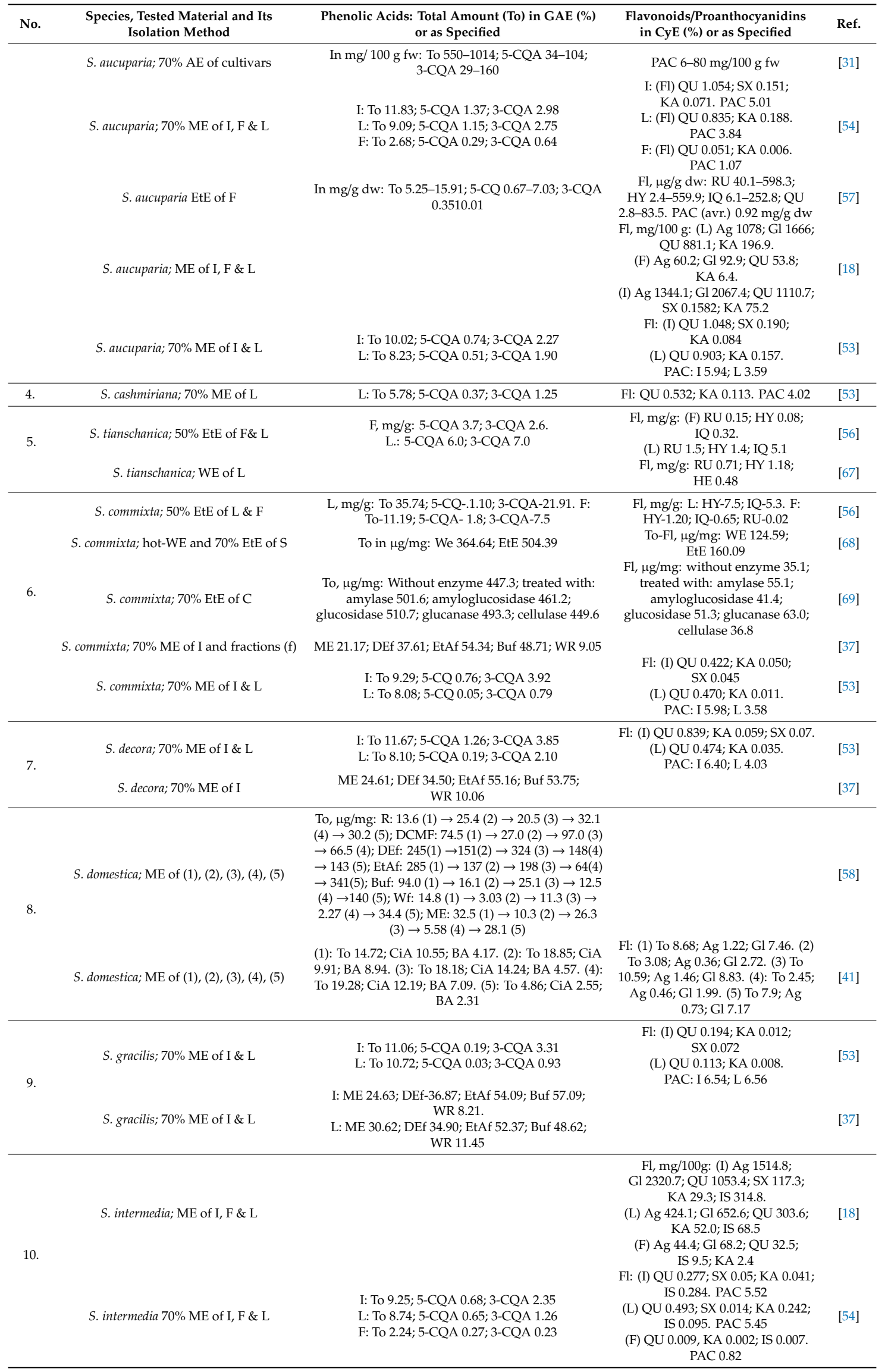


Table 2. Cont.

\begin{tabular}{|c|c|c|c|c|}
\hline No. & $\begin{array}{l}\text { Species, Tested Material and Its } \\
\text { Isolation Method }\end{array}$ & $\begin{array}{c}\text { Phenolic Acids: Total Amount (To) in GAE (\%) } \\
\text { or as Specified }\end{array}$ & $\begin{array}{l}\text { Flavonoids/Proanthocyanidins } \\
\text { in CyE (\%) or as Specified }\end{array}$ & Ref. \\
\hline \multirow{2}{*}{11.} & S. koehneana; ME of I \& L & $\begin{array}{l}\text { I: To } 11.67 ; 5-C Q A 1.98 ; 3-C Q A 2.05 \\
\text { L: To } 9.87 ; 5 \text { CQA-0.53; 3-CQA } 1.97\end{array}$ & \multirow[t]{2}{*}{$\begin{array}{c}\text { Fl: (I) QU 0.27; KA 0.02; SX } 0.05 . \\
\text { PAC } 6.86 \\
\text { L: QU 0.25; KA 0.11. PAC } 5.81\end{array}$} & [53] \\
\hline & S. koehneana; $70 \%$ ME of I \& L & $\begin{array}{l}\text { To: ME 26.38; DEf32.10; EtAf50.51; Buf 58.17; } \\
\text { WR 10.51 }\end{array}$ & & [37] \\
\hline 12. & S. pohuashanensis; $70 \% \mathrm{ME}$ of I \& L & $\begin{array}{l}\text { I: To } 11.32 ; 5 \text {-CQA } 0.7 ; 3 \text {-CQA } 2.48 \\
\text { L: To } 6.26 \text {; 5-CQA 0.12; 3-CQA } 0.67\end{array}$ & $\begin{array}{c}\text { Fl: I: QU-0.4; KA-0.04; SX-0.02. } \\
\text { L: QU-0.12; KA-0.03. PAC: I-7.67; } \\
\text { L-3.93 }\end{array}$ & [53] \\
\hline \multirow{2}{*}{13.} & S. pogonopetala; $70 \% \mathrm{ME}$ of $\mathrm{L}$ & To 10.9; 5-CQA 0.22; 3-CQA 1.63 & \multirow[t]{2}{*}{ Fl: QU 0.38; KA 0.26. PAC 5.89} & [53] \\
\hline & S. pogonopetala $; 70 \% \mathrm{ME}$ of $\mathrm{L}$ & $\begin{array}{c}\text { To: ME 24.03; Def 42.85; EtAf 53.29. Buf 39.56; } \\
\text { WR 10.38 }\end{array}$ & & [37] \\
\hline \multirow[t]{2}{*}{14.} & S. sambucifolia; $70 \%$ ME of I \& $\mathrm{L}$ & 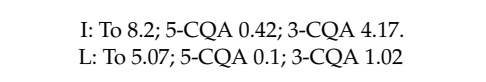 & \multirow{2}{*}{$\begin{array}{c}\text { Fl: (I) QU 0.81; KA } 0.06 \text {; SX } 0.13 . \\
\text { PAC } 3.79 \\
\text { (L) QU 0.16; KA } 0.01 . \text { PAC } 1.96 \\
\text { Fl: To } 0.002\end{array}$} & [53] \\
\hline & S. sambucifolia; EtE of F & To 0.733 & & [70] \\
\hline 15. & S. scalaris; $70 \%$ ME of I \& L & $\begin{array}{l}\text { I: To } 8.47 ; 5 \text {-CQA } 0.6 ; 3 \text {-CQA } 2.36 \\
\text { L: To } 4.23 ; 5 \text {-CQA } 0.36 ; 3 \text {-CQA } 1.24\end{array}$ & $\begin{array}{c}\text { Fl: (I) QU 0.34; KA 0.06; SX } 0.15 . \\
\text { PAC 5.68 } \\
\text { (L) QU 0.22; KA 0.13. PAC } 1.47\end{array}$ & [53] \\
\hline 16. & S. setschwanensis; $70 \% \mathrm{ME}$ of $\mathrm{L}$ & To 10.18; 5-CQA 0.22; 3-CQA 2.61 & Fl: QU 0.57; KA 0.31. PAC 5.56 & [53] \\
\hline 17. & S. sitchensis; $70 \%$ ME of I \& L & 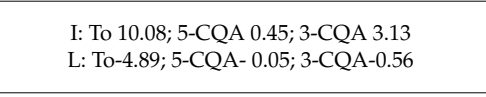 & $\begin{array}{c}\text { Fl: (I) QU 0.38; KA 0.02; SX } 0.05 \\
\text { L: QU-0.27; KA-0.02. PAC: I-7.14; } \\
\text { L-1.48 }\end{array}$ & [53] \\
\hline \multirow[b]{2}{*}{18.} & $\begin{array}{l}\text { S. torminalis var. torminalis; WE of F, ME } \\
\text { of F \& jam }\end{array}$ & $\begin{array}{c}\text { In } \mu \mathrm{g} / \mathrm{g} \text { dwe; WE-F: PCA 13.7; FA } 27.8 \\
\text { ME-F: PCA 23.2; FA } 62.6 \\
\text { Jam: PCA 5.92; FA } 13.3\end{array}$ & $\begin{array}{c}\text { Fl, } \mu \text { g/g dwe; WE-F: AF } 15.8 \\
\text { ME-F: AF 19.3; QU-3-O-gl 13.6; } \\
\text { HY 10.4 } \\
\text { Jam: AF 16.8; QU-3-O-gl 2.53; } \\
\text { HY 1.61 }\end{array}$ & [28] \\
\hline & $\begin{array}{l}\text { S. torminalis var. semitorminalis; } \mathrm{WE} \text { of } \mathrm{F}, \\
\text { ME of } \mathrm{F} \& \mathrm{jam}\end{array}$ & $\begin{array}{c}\text { WE-F: GA 5.69; FA 43.3; PCA } 4.61 \\
\text { ME-F: FA 38.3; PCA } 3.44 \\
\text { Jam: FA 18.4; PCA } 2.11\end{array}$ & $\begin{array}{c}\text { Fl, } \mu \mathrm{g} / \mathrm{g} \text { dwe; WE-F: AF 362; } \\
\text { KA-3-O-gl 2.34; QU 6.53; } \\
\text { QU-3-O-gl 3.33; Cat 10.6 } \\
\text { ME-F: AF 974; KA-3-O-gl 2.43; } \\
\text { QU 11; QU-3-O-gl 2.06 } \\
\text { Jam: AF 195; QU 3.76; } \\
\text { QU-3-O-gl 1.60 }\end{array}$ & [28] \\
\hline \multirow[b]{2}{*}{19.} & S. wilfordii; $70 \% \mathrm{ME}$ of $\mathrm{L}$ & \multirow{2}{*}{$\begin{array}{c}\text { To 12.31; 5-CQA 0.13; 3-CQA } 2.58 \\
\text { ME 29.93; DEf 53.13; EtAf 54.34; Buf 48.37; } \\
\text { WR 15.27 }\end{array}$} & \multirow[t]{2}{*}{ Fl: QU-0.88; KA-0.05. PAC: 5.31} & [53] \\
\hline & S. wilfordii; $70 \%$ ME of $\mathrm{L}$ & & & [37] \\
\hline
\end{tabular}

F-fruits; L-leaves; I-inflorescences; S-stems; C-cortex, B-bark. M-methanol; Et-ethanol; A-acetone; DCM-dichloromethane; DE-diethyl ether; Bu—butanol; EtA—ethyl acetate; W-water; E-extract; R-residue; $\mathrm{f}$-fraction. Total phenolic content is expressed in GAE (gallic acid equivalents); avr-average; fm-fresh mass; $\mathrm{Fl}$-flavonoids in \%; PAC—-proanthocyanidins in \% of CyE (cyanidin chloride equivalents); 3-CQA-chlorogenic acid; 5-CQA—neochlorogenic acid; GA—gallic acid; HC—hydroxycinnamic acid; CA—caffeic acid; $\mathrm{p}-\mathrm{c}-\mathrm{p}$-coumaric; HB-hydroxybenzoic; Gl—glycoside, Ag-aglycone, PCA—protocatechuic acid; CiA—cinnamic acids, BA—benzoic acids; FA-ferulic acid; AF-amentoflavone; QG-quercetin-3-O-glucoside; KA-3-O-gl-kaempferol-3-O-glucoside; Cat-catechin; QU-3-O-so-quercetin-3-O- $\beta$-sophoroside; QU-quercetin; KA-kaempferol; SX-sexangularetin. Unripe fruit (1), well matured on tree (2), matured for 1 week at room temperature (3), matured for 3 weeks at room temperature (4), fruit pulp from well matured fruits (5).

Sexangularetin was one of the most abundant flavonoid component in the inflorescences; S. aucuparia and S. scalaris contained $0.19 \%$ and $0.14 \% \mathrm{dw}$, respectively [53]. Epicatechin was reported in the leaves of many Sorbus spp. [71,72], as well as in the berries of S. aucuparia [60] and S. torminalis var. semitorminalis [28]. Hesperidin was found only in the leaves of $S$. tianschanica $[67,73]$. The highest levels of proanthocyanidins among the inflorescences of 12 tested species were found in the S. pohuashanensis and S. sitchensis, $7.67 \%$ and $7.14 \% \mathrm{CyE}$, respectively. Among the 17 leaf samples, S. gracilis had the highest concentration of proanthocyanidins, 6.56\% CyE [53]. Among the rowanberries, the highest content of proanthocyanidins was found in the fruits of S. aria, 1.80\% $\mathrm{CyE}$ [54]. Catechin and epicatechin were the main flavonoid components in the samples of $S$. decora stembark [74], rootsock [75], but also in the water extract of $S$. torminalis var. semitorminalis [28].

Quercetin content in methanol extract of $S$. torminalis var. semitorminalis was $11.0 \mu \mathrm{g} / \mathrm{g}$ while in water extract it was 2-fold lower, $6.53 \mu \mathrm{g} / \mathrm{g}$ [28]. The content of rutin in water and methanol extracts of S. aucuparia was found similar, 82.3 and $80.4 \mu \mathrm{g} / \mathrm{g} \mathrm{dw}$, respectively [28]. Hydroethanolic (70\%) extract of dried S. commixta stems and cortex contained higher by $50.43 \%$ total polyphenol and flavonoid content than water extract; the former also demonstrated stronger antioxidant capacity [68]. 
Exceptionally high content of amentoflavone was found in S. torminalis var. semitorminalis water and methanol extracts as well as in its jam, namely 362, 974, and $195 \mu \mathrm{g} / \mathrm{g} \mathrm{dw}$, respectively. However, its content in the extracts and jam of $S$. torminalis var. torminalis and $S$. aucuparia differed just slightly: it was $15.8,19.3$ and $16.8 \mu \mathrm{g} / \mathrm{g} \mathrm{dw}$ and 10.7, 11.9 and $8.4 \mu \mathrm{g} / \mathrm{g} \mathrm{dw}$, respectively [28]. Up to $119 \mu \mathrm{g} / \mathrm{g} \mathrm{dw}$ of quercetin-3-O-glucoside were reported in S. americana [55]. Typically, anthocyanins have been detected in the S. aucuparia cultivars however only in low concentrations, usually less than $1 \%$ of the total phenolics in the wild fruits [60]. Bobinaite et al. [59] reported that the total content of proanthocyanidins in S. aucuparia pomace water extract was 10.4 and 3.8 times, higher than that in the acetone and ethanol extracts, respectively.

\section{Antioxidant Potential of Sorbus spp.}

Plant material, suitable for cost-effective production of natural antioxidants should contain reasonable amount of polyphenolics (usually not less than $8-10 \% \mathrm{GAE} / \mathrm{dw}$ ), demonstrate comparatively strong antioxidant properties in several assay systems and exhibit as low as possible toxicity, which should be acceptable for human applications [53].

Large number of phytochemicals belonging to various classes of organic compounds have been identified in various Sorbus spp. [4]. The presence of significant amounts of polyphenolic antioxidants, mainly flavonoids and phenolic acids, has also been reported in Sorbus spp. (Table 2). Moreover, many authors observed good positive correlation between the concentration of phenolics, e.g., the sum of proanthocyanidins, caffeoylquinic acids and flavonoid aglycones and antioxidant properties $[31,57,58]$. Therefore, in many studies rowanberries exhibited significant antioxidant activity (Table 3), which was comparable or in some cases even higher than that of many other edible berries, such as chokeberries and bilberries [76]. Various methods have been applied for assessing antioxidant properties of rowanberries and their extracts, most frequently using the in vitro radical scavenging capacity assays and inhibition of lipid peroxidation [77], reducing power, chain-breaking potential of radical reactions [60] and others. The majority of studies investigated Sorbus fruits, leaves and inflorescences; however, antioxidant properties of tree bark and seed oil were also reported [46].

The main polyphenolic compounds responsible for antioxidant properties of rowanberries are phenolic acids (mostly caffeoylquinic acids), flavonols (quercetin, isoquercetin, hyperoside, rutin, catechin, epicatechin), anthocyanins (mainly cyanidin or pelargonidin glycosides), and proanthocyanidins [53,60]. In addition, many studies have reported several quercetin, sexangularetin (SX) and kaempferol (KA) glycosides in the fruits, inflorescences, leaves and stems of various Sorbus spp. (Table 2).

The stage of maturity [45], genotype [40], species [53], geographic origin [44], climatic environment, as well as storage conditions [78] and treatment [28] affect the composition of bioactive constituents. For example, Mrkonjić et al. [28] reported that among 12 identified in S. aucuparia and S. torminalis phenolic compounds chlorogenic acid was the most abundant in the former, while flavonoid amentoflavone in the latter one. The fruits of S. aucuparia better scavenged DPPH ${ }^{\bullet}$ (2,2-diphenyl-1-picrylhydrazyl), ${ }^{\bullet} \mathrm{NO}, \mathrm{O}_{2}{ }^{\bullet}, \mathrm{HO}^{\bullet}$ and inhibited lipid peroxidation (LP) than those of $S$. torminalis; however, both varieties of the latter species, namely torminalis and semitorminalis demonstrated almost identical antioxidant potential.

Many researchers have reported the correlation between the TPC and antioxidant capacity, particularly in case of using very popular chemical in vitro assays such as DPPH ${ }^{\bullet}$ ABTS $^{\bullet+}$ (2,2'-azinobis-(3-ethylbenzothiazoline-6-sulfonate) scavenging, FRAP (ferric reducing antioxidant power) and LPO (inhibition of lipid peroxidation). The ethyl acetate (EtOAc) extract of S. americana berries and other nine edible North American plants were tested for antioxidant activity using the $\mathrm{DPPH}^{\bullet}$ scavenging assay. DPPH${ }^{\bullet}$ scavenging value $\mathrm{IC}_{50}$ of $S$. americana was $113.96 \mu \mathrm{g} / \mathrm{mL}$; other in this study investigated plants, Gaultheria shallon and Sambucus cerulea exhibited stronger antioxidant capacity with $\mathrm{IC}_{50}$ values of 14.76 and $29.32 \mu \mathrm{g} / \mathrm{mL}$, respectively [36]. Methanol extracts of S. americana dried bark and leaves were remarkably stronger $\mathrm{DPPH}^{\bullet}$ scavengers with $\mathrm{EC}_{50}$ of $15.80 \mu \mathrm{g} / \mathrm{mL}$ [12] and 
$38.76 \mu \mathrm{g} / \mathrm{mL}$ [53], respectively. For comparison, these values for black tea and coffee were 15.19 and $40.32 \mu \mathrm{g} / \mathrm{mL}$, respectively [77].

Hukkanen et al. reported high antioxidant activity and phenolic contents in the fruits of several sweet rowanberry (S. aucuparia) cultivars, namely Burka, Dessertnaja, Eliit, Granatnaja, Kubovaja, Rosina, Rubinovaja, Titan, and Zholtaja: DPPH ${ }^{\bullet}$ scavenging capacity and FRAP values were in the ranges of 9.7-21.3 g fw/g radical and 61-105 mmol Fe(II)/g fw [31]. Olszewska et al. analysed different anatomical parts of S. aucuparia, S. aria and S. intermedia and found that S. aucuparia inflorescence demonstrated the highest antioxidant capacity: in FRAP and $\mathrm{ABTS}^{\bullet+}$ decolouration assays it was $2453.5 \mu \mathrm{mol} \mathrm{TE} / \mathrm{g} \mathrm{dw}$ and $83.05 \mathrm{mg} / \mathrm{L}$, respectively, while the $\mathrm{IC}_{50}$ in $\mathrm{DPPH}^{\bullet}$ scavenging assay was $18.05 \mu \mathrm{g} / \mathrm{mL}$. Respective values of $S$. aria fruit were $497.7 \mu \mathrm{mol} \mathrm{TE} / \mathrm{g} \mathrm{dw}$ (FRAP), $142.20 \mathrm{mg} / \mathrm{L}\left(\mathrm{ABTS}^{\bullet+}\right.$ ) and $95.31 \mu \mathrm{g} / \mathrm{mL}$ (DPPH ${ }^{\bullet}$ ) [54].

The same authors measured $\mathrm{DPPH}^{\bullet}$ scavenging of 16 Sorbus spp. and determined that the lowest $\mathrm{EC}_{50}$ values demonstrated methanolic extracts of S. aucuparia, S. pohuashanensis, S. decora, S. koehneana, S. commixta, S. gracilis, and S. sitchensis inflorescences and S. wilfordinci, S. pogonopetala, and S. gracilis leaves; they were in the ranges of $16.20-27.21 \mu \mathrm{g} / \mathrm{mL}$ and $15.23-20.71 \mu \mathrm{g} / \mathrm{mL}$, respectively. These results correlated with high total phenolic levels [53]. Mrkonjić et al. [28] observed that methanolic and water extracts and jams of $S$. aucuparia fruits were stronger antioxidants than S. torminalis.

Table 3. Bioactivity of selected Sorbus species.

\begin{tabular}{|c|c|c|c|c|c|}
\hline No. & $\begin{array}{l}\text { Species, Tested } \\
\text { Material and Its } \\
\text { Isolation Method }\end{array}$ & Antioxidant Activity $\mathrm{EC}_{50}(\mu \mathrm{g} / \mathrm{mL})$ or as Specified & TEAA, $\mathrm{mmol} / \mathrm{g}$ or LPO $\%$ & $\begin{array}{l}\text { FRAP, mmol } \mathrm{Fe}^{2+} / \mathrm{g} \text { or } \\
\text { as Specified }\end{array}$ & Ref. \\
\hline 1. & $\begin{array}{l}\text { S. alnifolia; } 75 \% \text { EtE } \\
\text { of } \mathrm{L}\end{array}$ & $\mathrm{DPPH}^{\bullet} 30.6$ & & & [39] \\
\hline \multirow[b]{2}{*}{2.} & $\begin{array}{l}\text { S. americana; } 70 \% \mathrm{ME} \\
\text { of } \mathrm{L}\end{array}$ & $\mathrm{DPPH}^{\bullet} 38.76$ & \multirow[t]{2}{*}{ TEAA-0.34; LPO-54.29 } & & [53] \\
\hline & $\begin{array}{l}\text { S. americana; } \mathrm{Et} \mathrm{AE} \text { of } \mathrm{F} \\
\text { S. americana } \mathrm{ME} \text { of } \mathrm{B}\end{array}$ & $\begin{array}{l}\mathrm{DPPH}^{\bullet} 113.9 \\
\mathrm{DPPH}^{\bullet} 15.8\end{array}$ & & & $\begin{array}{l}{[12]} \\
{[36]}\end{array}$ \\
\hline 3. & $\begin{array}{l}\text { S. aria } ; 70 \% \mathrm{ME} \text { of } \mathrm{I}, \\
\mathrm{L} \& \mathrm{~F} \\
\text { S. aria } \mathrm{EtE} \text { of } \mathrm{F}\end{array}$ & $\begin{array}{l}\mathrm{DPPH}^{\bullet}: \text { I } 42.05 ; \mathrm{L} \text { 50.17; F } 95.31 \\
\mathrm{DPPH}^{\bullet}, \mathrm{mg} / \mathrm{mL}: 0.49-2.50\end{array}$ & $\begin{array}{l}\text { TEAA: I 0.41; L 0.344; } \\
\text { F } 0.18\end{array}$ & I 1.394; L 1.119; F 0.498 & {$[54]$} \\
\hline \multirow{8}{*}{4.} & S. aucuparia; $70 \% \mathrm{ME}$ & $\begin{array}{l}\text { DPPH }{ }^{\bullet} \text { ME 8.93; DEf 5.53; EtAf 3.37; Buf 3.52; } \\
\text { WR 9.96 }\end{array}$ & $\begin{array}{l}\text { TEAA: ME 1.72; DEf 2.14; } \\
\text { EtAf 3.22; Buf 3.58; } \\
\text { WR 0.94 }\end{array}$ & \multirow[t]{2}{*}{$\begin{array}{l}\text { ME 4.43; DEf 9.30; EtAf } \\
\text { 12.77; Buf 10.84; WR 2.58 }\end{array}$} & [37] \\
\hline & $\begin{array}{l}\text { S. aucuparia; ME of } \mathrm{F} \\
\text { and cultivars }\end{array}$ & $\begin{array}{l}\text { ME-F, } \mathrm{DPPH}^{\bullet}, \mathrm{g} / \mathrm{kg} \mathrm{fm:} 6.73 ; \% \text { of inhibition: } \mathrm{HO}^{\bullet} \\
16.33 ; \mathrm{O}_{2}^{\bullet} 26.74 ; \bullet \mathrm{NO} 24.75 . \text { Cultivars: } \mathrm{DPPH}^{\bullet} \\
6.58-9.62 ; \% \text { of inhib.: } \mathrm{HO} \boldsymbol{\bullet}^{\bullet} 16.12-24.73 ; \mathrm{O}_{2} \\
27.19-34.02 ; \bullet^{\bullet} \mathrm{NO} 25.03-31.39\end{array}$ & $\begin{array}{l}\text { ME-F LPO, } \% \text { of inhibition: } \\
8.21 \text { Cultivars: } 7.93-13.12\end{array}$ & & [34] \\
\hline & S. aucuparia; $\mathrm{AE}$ of $\mathrm{F}$ & $\mathrm{DPPH}^{\bullet}, \mathrm{mmol} / \mathrm{kg} \mathrm{dw}: 357$ & \multirow{3}{*}{$\begin{array}{l}\text { LPO mg mL: WE-F - } 6.40 ; \\
\text { ME-F - } 7.38 ; \text { jam - } 4.08\end{array}$} & \multirow{3}{*}{$\begin{array}{l}\text { mmol } \mathrm{Fe}^{2+} / \mathrm{kg} \mathrm{dw}: 315.5 \\
\text { mg of AAE/g: WE-F: } \\
\text { 10.6. ME-F: } 11.2 . \\
\text { Jam: } 4.22 \\
0.061-0.105\end{array}$} & [49] \\
\hline & $\begin{array}{l}\text { S. aucuparia; WE of F, } \\
\text { ME of F \& jam }\end{array}$ & 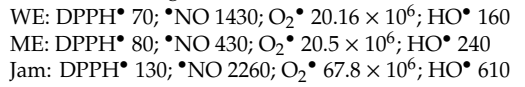 & & & [28] \\
\hline & $\begin{array}{l}\text { S. aucuparia (sweet } \\
\text { cultivars); } 70 \% \mathrm{AE}\end{array}$ & $\mathrm{DPPH}^{\bullet}, \mathrm{g} / \mathrm{g}: 21.3-9.7$ & & & [31] \\
\hline & $\begin{array}{l}\text { S. aucuparia; } 70 \% \mathrm{ME} \\
\text { of } \mathrm{I}, \mathrm{L}, \& \mathrm{~F}\end{array}$ & $\mathrm{DPPH}^{\bullet}:$ I 18.05; L 27.47; F 163.63 & \multirow{3}{*}{$\begin{array}{l}\text { TEAA: I } 0.956 ; \text { L } 0.628 \\
\text { F } 0.106 \\
\text { TEAA: I } 0.78 ; \text { L } 0.54 \\
\text { LPO: I } 68.34 ; \text { L } 58.69\end{array}$} & \multirow[t]{3}{*}{ I 2.454; L 2.148; F 0.442} & [54] \\
\hline & $\begin{array}{l}\text { S. aucuparia; } 70 \% \mathrm{ME} \\
\text { of I \& L }\end{array}$ & DPPH•: I 16.69; L 24.10 & & & [53] \\
\hline & S. aucuparia EtE of F & $\mathrm{DPPH}^{\bullet} 340-4260$ & & & [57] \\
\hline \multirow{2}{*}{5.} & S. cashmiriana & $\begin{array}{l}\text { In } \mu \mathrm{mol} / \mathrm{mL} ; \mathrm{DPPH}^{\bullet} 7.6-12.5 ; \mathrm{H}_{2} \mathrm{O}_{2} 15.4-18.6 \text {; } \\
\text { ABTS }^{\bullet+} 18.3-24.4\end{array}$ & & \multirow[t]{2}{*}{$\mu \mathrm{mol} / \mathrm{mL}: 11.3-23.8$} & [15] \\
\hline & $\begin{array}{l}\text { S. cashmiriana; } 70 \% \mathrm{ME} \\
\text { of } \mathrm{L}\end{array}$ & $\mathrm{DPPH}^{\bullet} 48.59$ & TEAA 0.27; LPO 53.59 & & [53] \\
\hline \multirow[t]{2}{*}{6.} & $\begin{array}{l}\text { S. commixta; hot-WE } \\
\text { of } \mathrm{S}\end{array}$ & 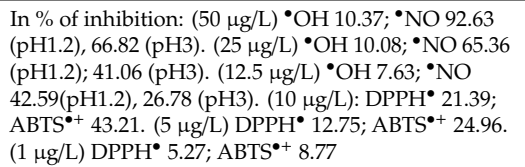 & & $\begin{array}{l}\text { In \%: } 50 \mu \mathrm{g} / \mathrm{L} 19.28 \\
25 \mu \mathrm{g} / \mathrm{L} 9.28 \\
12.5 \mu \mathrm{g} / \mathrm{L} 6.83\end{array}$ & [68] \\
\hline & $\begin{array}{l}\text { S. commixta; } \\
70 \% \text { EtE of S }\end{array}$ & 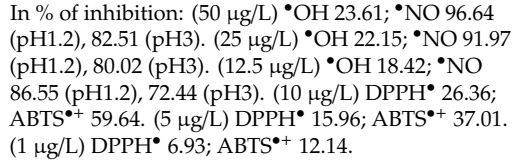 & & $\begin{array}{l}\text { In } \%: 50 \mu \mathrm{g} / \mathrm{L} 13.06 \\
25 \mu \mathrm{g} / \mathrm{L} 10.31 \\
12.5 \mu \mathrm{g} / \mathrm{L} 9.30\end{array}$ & [68] \\
\hline
\end{tabular}


Table 3. Cont.

\begin{tabular}{|c|c|c|c|c|c|}
\hline No. & $\begin{array}{l}\text { Species, Tested } \\
\text { Material and Its } \\
\text { Isolation Method }\end{array}$ & Antioxidant Activity $\mathrm{EC}_{50}(\mu \mathrm{g} / \mathrm{mL})$ or as Specified & TEAA, $\mathrm{mmol} / \mathrm{g}$ or $\mathrm{LPO} \%$ & $\begin{array}{l}\text { FRAP, } \mathrm{mmol} \mathrm{Fe}^{2+} / \mathrm{g} \text { or } \\
\text { as Specified }\end{array}$ & Ref \\
\hline & $\begin{array}{l}\text { S. commixta; } \\
70 \% \text { EtE of C }\end{array}$ & 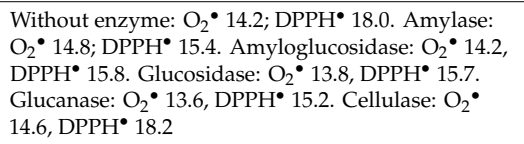 & & & [69] \\
\hline & $\begin{array}{l}\text { S. commixta; } 70 \% \mathrm{ME}, \mathrm{f} \\
\text { and } \mathrm{R}\end{array}$ & $\begin{array}{l}\text { DPPH•: ME 7.16; DEf 5.72; EtAf 3.52; Buf 3.53; } \\
\text { WR 9.66 }\end{array}$ & $\begin{array}{l}\text { TEAA: ME 1.70; DEf 2.14; } \\
\text { EtAf 2.62; Buf-3.40; } \\
\text { WR 1.26 }\end{array}$ & $\begin{array}{l}\text { ME 5.04; DEf 7.58; } \\
\text { EtAf 12.23; Buf 11.01; } \\
\text { WR 2.70 }\end{array}$ & [37] \\
\hline & $\begin{array}{l}\text { S. commixta; } 70 \% \\
\text { ME of I \& L }\end{array}$ & $\mathrm{DPPH}^{\bullet}$ : I 23.22; L 28.56 & $\begin{array}{l}\text { TEAA: I 0.56, L } 0.46 \\
\text { LPO: I } 78.21, \text { L } 58.65\end{array}$ & & [53] \\
\hline \multirow[t]{2}{*}{7.} & $\begin{array}{l}\text { S. decora; } 70 \% \mathrm{ME}, \mathrm{Fs} \\
\text { and R of I }\end{array}$ & $\begin{array}{l}\text { DPPH }: \text { ME 7.76; DEf 5.57; EtAf 3.44; Buf 3.17; } \\
\text { WR 9.84 }\end{array}$ & $\begin{array}{l}\text { TEAA: ME 1.79; DEf 2.67; } \\
\text { EtAf 3.98; Buf 3.55; } \\
\text { WR 1.21 }\end{array}$ & $\begin{array}{l}\text { ME 5.42; DEf 8.5; } \\
\text { EtAf 13.74; Buf 11.47; } \\
\text { WR 2.77 }\end{array}$ & {$[37]$} \\
\hline & $\begin{array}{l}\text { S. decora; } 70 \% \text { ME of I } \\
\& \mathrm{~L}\end{array}$ & $\mathrm{DPPH}^{\bullet}:$ I 16.20; L 27.21 & $\begin{array}{l}\text { TEAA: I 0.81; L } 0.48 \\
\text { LPO: I 70.99; L } 59.99\end{array}$ & & [53] \\
\hline 8. & $\begin{array}{l}\text { S. domestica; ME of (1), } \\
(2),(3),(4),(5)\end{array}$ & $\begin{array}{l}\mathrm{DPPH}^{\bullet}:(\mathrm{R}) 4829(1) \rightarrow 6290(2) \rightarrow 3720(3) \rightarrow \\
2730(4) \rightarrow 1810(5) . \text { DCMf: } 3600(1) \rightarrow \\
9880(2) \rightarrow 3820(3) \rightarrow 6010(4) . \text { DEf: } 997(1) \\
\rightarrow 1740(2) \rightarrow 825(3) \rightarrow 3280(4) \rightarrow 2970(5) . \\
\text { (EtAf) } 1780(1) \rightarrow 1750(2) \rightarrow 1840(3) \rightarrow 3170(4) \rightarrow 899(5) . \\
(\text { Buf } 588(1) \rightarrow 8000(2) \rightarrow 3750(3) \rightarrow 13200(4) \rightarrow 341(5) . \\
\text { Wf: } 4950(1) \rightarrow 39100(2) \rightarrow 5570(3) \rightarrow 39500(4) \rightarrow 2170(5) . \\
(M E) 2550(1) \rightarrow 10600(2) \rightarrow 1890(3) \rightarrow \\
20000(4) \rightarrow 1450(5)\end{array}$ & & & {$[58]$} \\
\hline \multirow[t]{2}{*}{9.} & $\begin{array}{l}\text { S. gracilis; } \\
70 \% \mathrm{ME} \text { of I \& L }\end{array}$ & $\begin{array}{l}\text { DPPH॰ (I) ME 7.93; DEf 5.39; EtAf 3.71; Buf 3.25; } \\
\text { WR 10.12. (L) ME 6.60; DEf 5.29; EtAf 3.70; Buf 3.83; } \\
\text { WR 9.54 }\end{array}$ & $\begin{array}{l}\text { TEAA: (I) ME 1.99; DEf } \\
\text { 2.71; EtAf 3.65; Buf 3.68; } \\
\text { WR 1.15. (L) ME 2.12; DEf } \\
\text { 2.14; EtAf 3.72; Buf 3.33; } \\
\text { WR 1.31 }\end{array}$ & $\begin{array}{l}\text { I: ME 5.36; DEf 9.34; EtAf } \\
\text { 13.06; Buf-9.92; WR 2.26. } \\
\text { (L) ME 6.2; DEf 8.72; } \\
\text { EtAf 12.94; Buf 11.05; } \\
\text { WR 2.98 }\end{array}$ & {$[37]$} \\
\hline & $\begin{array}{l}\text { S. gracilis; } 70 \% \text { ME of I } \\
\text { \& L }\end{array}$ & DPPH•: I 19.09; L 20.71 & $\begin{array}{l}\text { TEAA: I 0.68; L } 0.63 \\
\text { LPO: I 73.01; L } 70.72\end{array}$ & & {$[53]$} \\
\hline 10. & $\begin{array}{l}\text { S. intermedia; } 70 \% \mathrm{ME} \\
\text { of I, L \& F }\end{array}$ & $\mathrm{DPPH}^{\bullet}$ : I 25.41; L 30.71; F 198.69 & $\begin{array}{l}\text { TEAA: I } 0.679 ; \text { L } 0.572 ; \mathrm{F} \\
0.087\end{array}$ & I 2.123; L 1.512; F 0.298 & [54] \\
\hline \multirow[b]{2}{*}{11.} & $\begin{array}{l}\text { S. koehneana; } 70 \% \mathrm{ME} \\
\text { of I \& L }\end{array}$ & $\mathrm{DPPH}^{\bullet}$ : I 16.20; L 24.74 & $\begin{array}{l}\text { TEAA: I } 0.81 ; \text { L } 0.53 \\
\text { LPO: I } 73.34 ; \text { L } 54.15\end{array}$ & & {$[53]$} \\
\hline & $\begin{array}{l}\text { S. koehneana; } 70 \% \mathrm{ME} \\
\text { of I }\end{array}$ & $\begin{array}{l}\text { DPPH }{ }^{\bullet} \text { : ME 6.74; DEf 5.70; EtAf 3.46; Buf 3.15; } \\
\text { WR 9.71 }\end{array}$ & $\begin{array}{l}\text { TEAA: ME 2.08; DEf 2.60; } \\
\text { EtAf 3.56; Buf 3.94; } \\
\text { WR 1.29 }\end{array}$ & $\begin{array}{l}\text { ME 5.44; DEf 8.38; EtAf } \\
\text { 12.87; Buf 9.81; WR 2.54 }\end{array}$ & {$[37]$} \\
\hline 12. & $\begin{array}{l}\text { S. pohuashanensis; } 70 \% \\
\text { ME of I \& L }\end{array}$ & $\mathrm{DPPH}^{\bullet}:$ I 17.89; L 43.86 & $\begin{array}{l}\text { TEAA: I 0.73; L } 0.30 \\
\text { LPO: I } 68.69 ; \text { L } 50.21\end{array}$ & & {$[53]$} \\
\hline \multirow{2}{*}{13.} & $\begin{array}{l}\text { S. pogonopetala; } 70 \% \\
\text { ME of L }\end{array}$ & $\begin{array}{l}\text { DPPH }{ }^{\bullet} \text { : ME 6.84; DEf 4.89; EtAf 3.8; Buf 5.18; } \\
\text { WR } 9.83\end{array}$ & $\begin{array}{l}\text { TEAA: ME 1.81; DEf 2.28; } \\
\text { EtAf 3.44; Buf 2.96; } \\
\text { WR } 1.03\end{array}$ & $\begin{array}{l}\text { ME 5.54; DEf 10.92; EtAf } \\
\text { 11.42; Buf 8.67; WR 2.92 }\end{array}$ & {$[37]$} \\
\hline & $\begin{array}{l}\text { S. pogonopetala; } 70 \% \\
\text { ME of L }\end{array}$ & $\mathrm{DPPH}^{\bullet} 19.87$ & TEAA $0.66 ;$ LPO 74.73 & & [53] \\
\hline 14. & $\begin{array}{l}\text { S. sambucifolia; } 70 \% \mathrm{ME} \\
\text { of I \& L }\end{array}$ & $\mathrm{DPPH}^{\bullet}:$ I 28.03; L 52.63 & $\begin{array}{l}\text { TEAA: I 0.47; L } 0.25 \\
\text { LPO: I } 58.12 \text {; L } 54.03\end{array}$ & & [53] \\
\hline 15. & $\begin{array}{l}\text { S. scalaris; } 70 \% \text { ME of I } \\
\text { \& L }\end{array}$ & $\mathrm{DPPH}^{\bullet}$ : I 27.65; L 57.86 & $\begin{array}{l}\text { TEAA: I 0.47; L } 0.23 \\
\text { LPO: I 55.23; L } 41.70\end{array}$ & & {$[53]$} \\
\hline 16. & $\begin{array}{l}\text { S. setschwanensis; } 70 \% \\
\text { ME L }\end{array}$ & $\mathrm{DPPH}^{\bullet} 23.30$ & TEAA 0.56; LPO 63.77 & & [53] \\
\hline 17. & $\begin{array}{l}\text { S. sitchensis; } 70 \% \mathrm{ME} \text { of } \\
\text { I \& L }\end{array}$ & $\mathrm{DPPH}^{\bullet}:$ I $20.75 ;$ L 54.23 & $\begin{array}{l}\text { TEAA: I 0.63; L } 0.24 \\
\text { LPO: I } 68.26 ; \text { L } 53.13\end{array}$ & & [53] \\
\hline 18. & $\begin{array}{l}\text { S. torminalis (L.) Crantz } \\
\text { var. torminalis; WE of } \mathrm{F} \text {, } \\
\text { ME of } \mathrm{F} \& \text { jam }\end{array}$ & 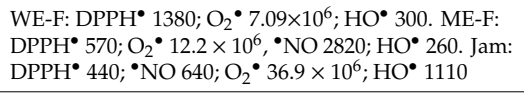 & & $\begin{array}{l}\text { mg AAE/g: WE-F 1.11; } \\
\text { ME-F 2.12; jam: } 3.1\end{array}$ & [28] \\
\hline 19. & $\begin{array}{l}\text { S. torminalis var. } \\
\text { semitorminalis; WE of } \mathrm{F} \text {, } \\
\text { ME of F \& jam }\end{array}$ & 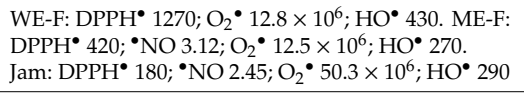 & LPO, mg mL: jam 3.02 & $\begin{array}{l}\text { mg AAE/g: WE-F 2.12; } \\
\text { ME-F 3.81; jam } 6.41\end{array}$ & {$[28]$} \\
\hline \multirow[t]{2}{*}{20.} & $\begin{array}{l}\text { S. wilfordii; } 70 \% \mathrm{ME} \\
\text { of } \mathrm{L}\end{array}$ & $\begin{array}{l}\text { DPPH॰: ME 6.01; DEf 3.67; EtAf 3.45; Buf 3.28; } \\
\text { WR 9.04 }\end{array}$ & $\begin{array}{l}\text { TEAA: ME 2.24; DEf 2.97; } \\
\text { EtAf 3.41; Buf 2.83; } \\
\text { WR 1.51 }\end{array}$ & $\begin{array}{l}\text { ME 6.78; DEf 11.60; EtAf } \\
\text { 12.55; Buf 10.99; WR } 4.03\end{array}$ & {$[37]$} \\
\hline & $\begin{array}{l}\text { S. wilfordii; } 70 \% \mathrm{ME} \\
\text { of } \mathrm{L}\end{array}$ & $\mathrm{DPPH}^{\bullet} 15.23$ & TEAA: L-0.86. LPO-86.92 & & {$[53]$} \\
\hline
\end{tabular}

$\mathrm{DPPH}^{\bullet}-2,2$-diphenyl-1-picrylhydrazyl free radical scavenging capacity; $\mathrm{ABTS}^{\bullet+}-2,2^{\prime}$-azinobis-(3ethylbenzothiazoline-6-sulfonate) radical cation decolouration assay; TEAA-trolox equivalent antioxidant activity, mmol/g; LPO-inhibition of lipid peroxidation, \%; FRAP—ferric reducing antioxidant power. E-extract; $\mathrm{f}$-fraction; R-residue; Et—ethanol; M-methanol; DE—diethyl ether; $\mathrm{Bu}$-butanol; W—water; EtA—ethyl acetate; A-acetone; DCM-dichloromethane. I-inflorescences; L-leaves; F-fruits; S-stems; C—cortex, B-bark; $\mathrm{fm}$-fresh mass. Unripe fruit (1), well matured on tree (2), matured for 1 week at room temperature (3), matured for 3 weeks at room temperature (4), fruit pulp from well matured fruits (5). 
In order to identify the ability of different solvents to recover antioxidants from $S$. aria leaves various extracts were tested by $\mathrm{DPPH}^{\bullet}$ scavenging method. Among the tested isolates, the $\mathrm{EC}_{50} \mathrm{Value}$ of ethyl acetate extract $(2.99 \mathrm{mg} / \mathrm{L})$, which contained $11.8 \%$ isoquercitrin, $6.0 \%$ astragalin, and $3.81 \%$ chlorogenic acid, was almost similar to reference antioxidant isoquercitrin, $\mathrm{EC}_{50} 2.76 \mathrm{mg} / \mathrm{L}$ [65]. Five strongly active constituents, namely isoquercitrin, rutin, quercetin 3-glucoside-7-rhamnoside, chlorogenic and neochlorogenic acids were found to be major components and principally responsible for the radical scavenging capacity of $S$. aria extracts [65]. Two interesting new coumarins, cashmins A (1) and B (2) were isolated from the methanolic extract of S. cashmiriana. Both compounds demonstrated outstanding antioxidant activity in $\mathrm{H}_{2} \mathrm{O}_{2}\left(\mathrm{IC}_{50} 15.4\right.$ and $\left.18.6 \mu \mathrm{mol} / \mathrm{mL}\right)$, as well as in $\mathrm{ABTS}^{\bullet+}$ scavenging

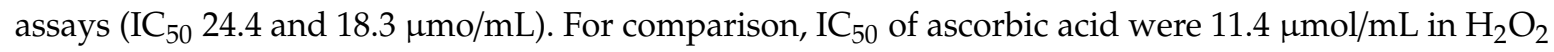
and $6.5 \mu \mathrm{mol} / \mathrm{mL}$ in $\mathrm{ABTS}^{\bullet+}$ assays [15].

Bae et al. [69] tested the effects of treatment with carbohydrate hydrolases on the composition of TPC and flavonoids, as well as antioxidative activity of ethanol extract of dried S. commixta cortex. Amyloglucosidase, $\alpha$-amylase, $\alpha$-glucosidase and $\beta$-glucanase increased the contents of extractable polyphenols and flavonoids, as well as the $\mathrm{DPPH}^{\bullet}$ scavenging capacity; particularly in case of applying $\beta$-glucanase [69].

Raudone et al. [71] detected twenty four constituents in the leaf samples of S. anglica, S. aria, S. arranensis, S. aucuparia, S. austriaca, S. caucasica, S. commixta, S. discolor, S. gracilis, S. hostii, S. semi-incisa and $S$. tianschanica, using ultra high performance liquid chromatography. Reducing activity of detected constituents was identified by the post-column FRAP assay; the highest total antioxidant activities of $175.3,169.2$ and $148.11 \mu \mathrm{mol} \mathrm{TE} / \mathrm{g} \mathrm{dw}$ were determined for S. commixta, S. discolor and S. gracilis, respectively.

Ethanol recovered antioxidants from $S$. commixta stems more effectively than hot water with the values of 504.39 and $364.64 \mu \mathrm{g} / \mathrm{mg}$, respectively. Similarly, ethanol extracts demonstrated slightly higher antioxidant activities than water extracts in $\mathrm{Fe}^{2+}$ chelating, $\mathrm{DPPH}^{\bullet}, \mathrm{ABTS}^{\bullet+}$, hydroxyl and nitrite radical scavenging assays [68]. Extraction and fractionation of $S$. domestica fruits harvested at five different maturity stages gave the products with scavenging capacity in the range of $0.341-39.5 \mathrm{mg}$ dwe/mg DPPH ${ }^{\bullet}$ and the following order: water $<<$ dichloromethane $<$ ethyl ether $<$ ethyl acetate [58]. The fractions recovered with organic solvents possessed greater radical scavenging capacity than trolox, while the unripe fruits provided more antioxidants than the well-matured berries at room temperature. Finally, radical scavenging values strongly correlated with the total phenolic content in the fractions of S. domestica [58]. Olszewska et al. demonstrated that strong antioxidant fractions might be obtained from $70 \%$ methanol extracts of inflorescences and/or leaves of seven Sorbus spp. by using different solvents in a separatory funnel. n-Butanol and ethyl acetate gave the fractions with outstanding antioxidant capacity in the all applied assays: EC $_{50} 3.2-5.2 \mu \mathrm{g} / \mathrm{mL}$ in DPPH${ }^{\bullet}, 2.8-4.0 \mathrm{mmol} \mathrm{TE} / \mathrm{g}$ in $\mathrm{ABTS}^{\bullet+}$, 9.8-13.7 mmol Fe${ }^{2+} / \mathrm{g}$ in FRAP and 39.6-58.2\% GAE in Folin-Ciocalteu [37]. Consequently, properly selected solvents may provide promising antioxidants for food and medicinal applications.

The fruits and jam of $S$. aucuparia and two varieties of $S$. torminalis, were assayed for $\mathrm{DPPH}^{\bullet}$, $\bullet \mathrm{NO}, \mathrm{HO}^{\bullet}$ and $\mathrm{O}_{2}{ }^{\bullet}$ scavenging capacity, FRAP, and $\mathrm{Fe}^{2+}$ /ascorbate induced LP inhibition. As already mentioned, $S$. aucuparia extracts were found to be the most effective almost in all tests, except for the assay toward the neutralisation of $\mathrm{O}_{2}{ }^{\bullet-}$ when $S$. torminalis var. torminalis was the most potent. S. torminalis var. torminalis and semitorminalis showed similar antioxidant activity, however, var. torminalis had a slightly better antiradical power towards ${ }^{\bullet} \mathrm{NO}, \mathrm{O}_{2}^{\bullet-}$ and $\mathrm{HO}^{\bullet}$, while the extracts of semitorminalis acted more effectively in scavenging $\mathrm{DPPH}^{\bullet}$, inhibiting LP and reducing $\mathrm{Fe}^{2+}$ [28]. Antioxidant capacity of extracts depends also on the nature of the assay as well as the polarity of solvent. For example, the results of Bobinaite et al. demonstrated superior antioxidant capacity of $S$. aucuparia pomace water extract in the all test systems: in DPPH ${ }^{\bullet}$, FRAP and ORAC (oxygen radical absorbance capacity) assays it was $309 \mu \mathrm{mol} \mathrm{TE} / \mathrm{g}, 323 \mu \mathrm{mol} \mathrm{TE} / \mathrm{g}$ and $263 \mathrm{mg} \mathrm{TE} / \mathrm{g}$, respectively; while ethanol extract was the next with its $\mathrm{DPPH}^{\bullet}$ and ORAC values of $103 \mu \mathrm{mol} \mathrm{TE} / \mathrm{g}$ and $201 \mathrm{mg}$ TE/g, respectively [59]. 


\section{Toxic Constituents of Rowanberries}

Parasorbic acid, an important inhibitor of germination, has been reported in the fruits and seeds of S. aucuparia at the level of $4-7 \mathrm{mg} / \mathrm{g}$ and $0.08-0.12 \mathrm{mg} / \mathrm{g} \mathrm{fw}$, respectively [79]. This compound irritates the gastric mucosa and, if consumed at larger amounts, can cause indigestion and kidney damage to humans. However, heat treatment or freezing modifies the parasorbic acid into nontoxic sorbic acid. Parasorbic acid is sensitive to changes of temperature and brakes into safe compounds if the berries are picked after the first frost [34]. The parasorbic acid is almost absent in the cultivated hybrids. The other toxic component in rowanberries is the cyanogenic glycoside prunasin, which is derived from the amino acid phenylalanine; $1 \mathrm{~g}$ of the prunasin can liberate $91.5 \mathrm{mg} \mathrm{HCN}$ (hydrogen cyanide). Thus, HCN from the seeds of rowanberries, when formed at the levels exceeding 2-3 mg/L, can cause respiratory failure and even death [80]. Therefore, while processing the rowanberry pomace, the separation of the seeds would be essential.

\section{Promising Health Benefits and Related Applications in Foods, Nutraceuticals and Pharmaceuticals}

It is evident that among phytochemicals and other nutrients, polyphenolic compounds and ascorbic acid may be considered as the most valuable health beneficial constituents, which have been reported in various anatomical parts of Sorbus spp. The polyphenolics, which may influence the colour and flavour, have demonstrated antioxidant [54,81], antidiabetic [11,82] anti-hyperlipidemic [83], anti-inflammatory [84], antimicrobial [85], anticancer [86,87] antiviral [67], antifungal [79], antitumoral [88], anti-periodontal [89], and anti-osteoarthritis [90] effects, as well as vasoprotective [84], neuroprotective [26,91,92], cardioprotective [36], hepatoprotective [7], properties and COX-2 (cyclooxygenase-2) inhibitory [93] activities. Many of these activities are correlated to antioxidant capacity of bioactive compounds, which at cellular level may neutralize excessive reactive oxygen species, and thereby protect important biomolecules in the conditions of oxidative stress, which can cause cellular injury and development of chronic diseases. Therefore, it has been hypothesized that antioxidant-rich diets might play an important role in neutralising the excessive reactive oxygen species [11]. This hypothesis and increasing amount of evidence in favour of it have encouraged many researchers to test many novel plant-based phytochemicals as natural candidates for developing health beneficial exogenous antioxidants. The other important role of antioxidants is to protect foods and other sensitive to oxidation products during processing and storage in order to extend their shelf life and improve the quality and safety [94]. Compared to pure synthetic compounds natural preparations of phenolic antioxidants can be more effective due to the synergistic effects of various molecules present in the plant-based products. In addition, natural ingredients are usually safer than their synthetic counterparts and therefore are preferred by the consumers [11].

The application of plant-based polyphenolic substances in lipid-containing foods, cosmetics, and medicinal products is hampered by their high polarity (hydrophilicity), which makes them poorly soluble in the lipid medium, which is composed mainly of triacylglycerols. Therefore, for increasing product lipophilicity some studies [94-96] applied derivatisation of phenolic compounds by attaching medium or long chain alkyl molecules. For instance, the lipophilised phenolic extract of S. aucuparia was more effective inhibitor of rapeseed oil oxidation during 7-day storage than the untreated one: it reduced peroxide value by $43 \%$ and improved the solubility of the phenolics during frying [95]. Hydrophilic fraction of rowanberry pomace contained most of the polyphenolic antioxidants, while lipophilic seed extracts could be beneficial as nutraceutical and cosmetic agents due to the high content of polyunsaturated fatty acids and carotenoids [97].

Water extracts of berries containing high amounts of low molecular weight proanthocyanidins, which were tested as the inhibitors of colon cancer-induced angiogenesis, turned out to be superior in reducing Caco-2 cell viability [59]. Due to the significant content of bioactive phenolics in fruits, the wild rowanberries inhibited lipid oxidation both in liposomes and in emulsions [31]. Aqueous methanol extracts of $S$. aucuparia fruits were potent antioxidants while the extracts of both 
S. torminalis varieties, namely torminalis and semitorminalis effectively inhibited the growth of E. coli, var. torminalis being the best inhibitor of Staphylococcus aureus [28]. Polyphenols from two hybrid cultivars of S. aucuparia, Zoltaja and Granatnaja also delayed pathogenic E. coli growth. The phenolic extracts of wild rowanberries and cultivated breed Burka had an inhibitory effect on hemagglutination of E. coli HB101 (pRR7), which expresses the M hemagglutinin [60]. S. aucuparia berry extract isolated with acidified acetone also demonstrated high activity against Salmonella enterica ssp. enterica ATCC BAA-2162, and Pseudomonas aeruginosa ATCC 9027; it also exhibited moderate activity towards the two Listeria monocytogenes strains and Proteus vulgaris [66]. Water extract of S. aucuparia fruit inhibited the growth of Gram-positive E. faecalis, S. aureus and Gram-negative S. enterica, as well as the viability of C. freundii and B. cereus [59]. These findings prove that $S$. aucuparia extracts express strong antimicrobial activity against a wide scale of microorganisms and possess the high mitogenic activity expressed as the stimulating effect on hamster lymphocyte proliferation [66]. Water and methanol extracts of S. aucuparia fruits were also effective in the inhibition of acetylcholinesterase (AChE) and exhibited in vitro cytotoxicity in SRB assay, using tumour HeLa, MCF7 and HT-29 and healthy MRC-5 cell lines; however, they didn't exhibit selectivity towards tumour cell lines [28].

The content of chlorogenic acid in sweet rowanberries can reach up to $200 \mathrm{mg} / 100 \mathrm{~g}$, which is comparable with Arabica variety coffee beans, the richest source of this phenolic acid containing $280 \mathrm{mg} / 100 \mathrm{~g}$ [31]. Chlorogenic acids have been associated with a decreased risk of type 2 diabetes (T2D); they hydrolyse to caffeic acid, which reduces glucose absorption and oxidative stress in vitro and inhibits glucose-6-phosphate translocase, thereby decreasing glucose output in the liver. Intact chlorogenic acids are poorly absorbed in the small intestine, while the released after hydrolysis cinnamic acids are effectively absorbed with the help of enzymes in the colon depending on the precursor chlorogenic acid type and individual characteristics of a person [98]. Consequently, caffeoylquinic acid derivatives isolated from $S$. commixta fruits might be used for the regulation of diabetic complications and other pathogenic complications. These compounds also showed the most potent inhibitory effect against formation of the advanced glycation end products (AGE); neo-chlorogenic, crypto-chlorogenic, and chlorogenic acid exhibited potent inhibitory effects against peroxynitrite in radical scavenging assay [99].

Boath et al. [100] have reported that $S$. aucuparia fruits inhibited $\alpha$-glucosidase with $\mathrm{IC}_{50}$ value $30 \mu \mathrm{g}$ $\mathrm{GAE} / \mathrm{mL}$ and were as effective as the pharmaceutical inhibitor acarbose for maintaining post-prandial glycemic control in T2D. Lately berry extracts of 16 different Sorbus species of subgenus Sorbus and Aria were tested for their $\alpha$-amylase and $\alpha$-glucosidase inhibitory activity. The study included S.aucuparia, S. aucuparia f. xanthocarpa, S.commixta, S. commixta var. rufo-ferruginea, S. decora, S. discolor, S. hybrida, S. koehneana, S. vilmorinii and crossbreeds S. aucuparia $\times$ americana, Sorbus $\times$ meinichii, Sorbus $\times$ splendida (from subgenus Sorbus) and S. alnifolia, S. folgneri, S. latifolia, S. minima, S. norvegica (from subgenus Aria). The berry extract of $S$. norvegica, which belongs to subgenus Aria, also inhibited $\alpha$-amylase and $\alpha$-glucosidase and therefore was used in an oral starch tolerance test in streptozotocin (STZ)-treated C57BL/6 mice; administration of $900 \mathrm{mg}$ extract daily demonstrated anti-hyperglycemic activity, which however was 36 times lower than in case of clinically used acarbose [24]. Thus, the berries of $S$. norvegica (subgenus Aria) may have some prospects in management T2D.

Twenty-nine different extracts, fractions and residues obtained from S. domestica fruits, harvested at 5 maturity phases were assessed for their in vitro inhibitory capacity of a rate-limiting enzyme aldose reductase [36,47]. Diethyl ether and ethyl acetate fractions effectively inhibited aldose reductase and the effect was associated with the high content of flavonoids and hydroxycinnamic acid esters determined in the extracts by liquid chromatography with diode array detector and mass spectrometer (LC-DAD-MS). The authors concluded that consumption of S. domestica fruit might be a promising way to reduce the occurrence of long-term complications of T2D, particularly at the early disease stages. The fractions of diethyl ether, ethyl acetate and dichloromethane of S. domestica were also noted as potential antioxidants to be used in food and medicinal preparations [36,47]. In addition, 
Bailie et al. [11] suggested that both flavonoids and terpenoids could offer benefits to treat a number of T2D symptoms.

Several studies reported the effects of Sorbus bioactives on cancer cell lines and some disease biomarkers. Thus, vanillic acid 4-O- $\alpha$-L-rhamnopyranoside, protocatechuic acid anhydride and trivanilloyl-(1,3,4-trihydroxybenzoyl) ester, which were the predominant antioxidants of the S. domestica fruits, make it potentially useful for the mitigation of several diseases, such as Clostridium difficile infection, inflammatory bowel and irritable bowel syndrome [101]. Ethanolic S. commixta fruit extract remarkably reduced the viability of human lung cancer cell lines through the induction of apoptosis irrespective of their p53 status [102]. Another study reported that ethyl acetate fraction of S. commixta exhibited considerable inhibition against thrombin, prothrombin, blood coagulation factors and platelet aggregation, without haemolysis activity at the doses up to $0.5 \mathrm{mg} / \mathrm{mL}$ and therefore, has the potential to be used as a new anti-coagulation agent [103]. The juice of $S$. sambucifolia provoked differentiation of HL-60 leukemic cells to monocyte/macrophage characteristics in a concentration-dependent manner as denoted by histochemical and biochemical assays; it was suggested that these findings are promising for developing new agents suitable for differentiation therapy of leukaemia with fewer side effects [70]. The S. umbellata (Desf.) Fritsch var. umbellata leaf extract demonstrated dose-dependent cytotoxic effect to A549 and MCF-7 cells in MTT assay, while the highest cell proliferation inhibition was observed for the $\mathrm{A} 549,71.8 \%$ at $150 \mu \mathrm{g} / \mathrm{mL}$ [104].

Sakuranetin isolated from S. commixta plant actively inhibited rhinovirus-3 (HRV3) replication and at $100 \mu \mathrm{g} / \mathrm{mL}$ exhibited higher than $67 \%$ antiviral activity without cytotoxicity in epithelioid carcinoma cervix (HeLa) cells; hence, it may be promising in developing novel drugs for treating HRV3 infections [105]. Water extract of the dried S. commixta inner stem bark suppressed the production of ${ }^{\bullet} \mathrm{NO}$ and prostaglandins at the transcriptional levels, thus acting as an anti-inflammatory remedy for ear oedema formation, which was induced by arachidonic acid in mouse. A targeted blockage of protein kinase B translocation and its upstream signalling pathways was suggested as a possible therapeutic approach to develop anti-inflammatory drugs in the treatment of chronic diseases [84]. Furthermore, lupeol isolated, from the stem bark of S. commixta showed significant inhibitory effects on osteoclastogenesis; therefore, addition of S. commixta and lupeol could be used for bone diseases, such as osteoporosis, Paget's disease, osteolysis associated with periodontal disease, and multiple myeloma [38].

The treatment of $S$. commixta cortexes by $\beta$-glucanase increased extract antioxidant activity, while its application resulted in the enhanced viability of human dermal fibroblasts exposed to ultraviolet (UV) light [69]. Furthermore, Kim et al. tested the leaf extract of S. alnifolia, among the others, to develop new natural cosmetic ingredients with antioxidant activity. As a result, the trials proved that the extract of S. alnifolia exhibited $87 \%$ inhibition of elastase activity when applied at $1 \mathrm{mg} / \mathrm{mL}$. This result may provide the relevant application of plant-based inhibitors of general elastase in cosmetics with effects for UV-irradiated and dry skin [106].

The methanol extracts of the dried stems and twigs of S. alnifolia contributed for protection against chemically and genetically induced dopaminergic neurodegeneration. Moreover, methanol extract of S. alnifolia plant increased food-sensing functions in the dopaminergic neuron degraded worms by $58.4 \%$ hereby prolonging the average lifespan by $25.6 \%$. Therefore, the extract of S. alnifolia can be a useful candidate for the treatment of Parkinson's disease [26].

\section{Conclusions and Further Perspectives}

Polyphenolic antioxidants are among the most popular topics in characterisation of different Sorbus spp. anatomical parts. Since Sorbus polyphenols (proanthocyanidins, chlorogenic acid isomers and flavonols) are recognized as potent antioxidants and health beneficial phytochemicals, and considering the significant phenolic content in various Sorbus spp., it can be concluded that their products could be an excellent sources of natural antioxidants [54]. Such bioactives may be useful both for protecting foods against oxidation/microbial spoilage and providing health benefits to 
the consumers by incorporation of Sorbus preparations into functional foods, nutraceuticals and/or cosmeceuticals. The results of current review confirm the specific phenolic composition and antioxidant activity of different plant parts of numerous Sorbus spp. All parts of S. commixta, the fruit, leaves and inflorescences of S. aria, S. aucuparia, S. sambucifolia, the leaves and inflorescences of S. gracilis and S. koehneana and the leaves of $S$. wilfordii and $S$. pogonopetala may be distinguished as the materials demonstrating outstanding antioxidant effect.

However, more systematic studies are required for developing convenient and acceptable to consumer applications of Sorbus ingredients in foods and/or food supplements. Some studies have proved that the products of rowanberries demonstrate antioxidant activity and can be considered as a good source of antioxidants in the diet; however, these studies are not sufficient for wider applications of Sorbus. The production of functional foods and nutraceuticals from selected Sorbus spp. is envisaged to impart valuable biological effects, especially those related to immunity and health.

Author Contributions: V.S. collecting literature sources, writing-original draft preparation and editing; P.R.V. methodology, collecting literature sources, writing-review and editing, supervision; R.B. writing-review and editing, supervision. All authors have read and agreed to the published version of the article.

Funding: This research received no external funding.

Acknowledgments: This work is supported by VALORTECH project, which has received funding from the European Union's Horizon 2020 Research and Innovation Program under grant agreement No 810630.

Conflicts of Interest: The authors declare no conflict of interests.

\section{References}

1. Vazquez-Flores, A.A.; Martinez-Gonzalez, A.I.; Alvarez-Parrilla, E.; Díaz-Sánchez, Á.G.; Rosa, L.A.; González-Aguilar, G.A.; Aguilar, C.N. Proanthocyanidins with a low degree of polymerization are good inhibitors of digestive enzymes because of their ability to form specific interactions: A hypothesis. J. Food Sci. 2018, 83, 2895-2902. [CrossRef] [PubMed]

2. Singh, J.; Metrani, R.; Shivanagoudra, S.R.; Jayaprakasha, G.K.; Patil, B.S. Review on bile acids: Effects of the gut microbiome, interactions with dietary fiber, and alterations in the bioaccessibility of bioactive compounds. J. Agric. Food Chem. 2019, 67, 9124-9138. [CrossRef] [PubMed]

3. Robertson, K.R.; Phipps, J.B.; Rohrer, J.R.; Smith, P.G. A synopsis of genera in Maloideae (Rosaceae). Syst. Bot. 1991, 16, 376-394. [CrossRef]

4. Sołtys, A.; Galanty, A.; Podolak, I. Ethnopharmacologically important but underestimated genus Sorbus: A comprehensive review. Phytochem. Rev. 2020, 19, 491-526. [CrossRef]

5. Poyrazoğlu, E.S. Changes in ascorbic acid and sugar content of rowanberries during ripening. J. Food Qual. 2004, 27, 366-370. [CrossRef]

6. Miletic, R.; Paunovic, S.M. Research into service tree (Sorbus domestica L.) population in eastern Serbia. Genetika 2012, 44, 483-490. [CrossRef]

7. Fomenko, S.E.; Kushnerova, N.F.; Sprygin, V.G.; Drugova, E.S.; Momot, T.V. Chemical composition and biological action of rowanberry extract. Russ. J. Bioorg. Chem. 2016, 42, 764-769. [CrossRef]

8. Hejcman, M.; Hejcmanová, P.; Pavlů, V.; Thorhallsdottirl, A.G. Nutritive value of leaf fodder from the main woody species in Iceland. In Grassland Science in Europe, Vol. 19-EGF at 50: The Future of European Grasslands; Hopkins, A., Collins, R.P., Fraser, M.D., King, V.R., Lloyd, D.C., Moorby, J.M., Robson, P.R.H., Eds.; European Grassland Federation EGF: Zürich, Switzerland, 2014; pp. 566-568.

9. USDA National Rersources Conservation Service. Available online: http://plants.usda.gov (accessed on 27 August 2020).

10. Ayupbek, A.; Hu, K.-L.; Aisa, H.A. Chemical constituents from the leaves of Sorbus tianschanica. Chem. Nat. Compd. 2012, 48, 133-134. [CrossRef]

11. Bailie, A.; Renaut, S.; Ubalijoro, E.; Guerrero-Analco, J.A.; Saleem, A.; Haddad, P.; Arnason, J.T.; Johns, T.; Cuerrier, A. Phytogeographic and genetic variation in Sorbus, a traditional antidiabetic medicine-Adaptation in action in both a plant and a discipline. PeerJ 2016, 2, 1-22. [CrossRef] 
12. Mccune, L.M.; Johns, T. Antioxidant activity in medicinal plants associated with the symptoms of diabetes mellitus used by the indigenous peoples of the North American boreal forest. J. Ethnopharmacol. 2002, 82, 197-205. [CrossRef]

13. Moon, S.C.; Choi, H.J.; Chung, T.W.; Lee, J.H.; Lee, S.O.; Jung, M.H.; Kim, B.J.; Choi, J.Y.; Ha, K.T. Sorbus commixta water extract induces apoptotic cell death via a ROS-dependent pathway. Oncol. Lett. 2018, 16, 4193-4200. [CrossRef] [PubMed]

14. Bhatt, L.R.; Bae, M.S.; Kim, B.M.; Oh, G.S.; Chai, K.Y. A chalcone glycoside from the fruits of Sorbus commixta Hedl. Molecules 2009, 14, 5323-5327. [CrossRef] [PubMed]

15. Khan, S.; Fatima, I.; Kazmi, M.H.; Malik, A.; Afza, N.; Iqbal, L.; Latif, M. Cashmins A and B, potent antioxidant coumarins from Sorbus cashmiriana. Chem. Nat. Compd. 2015, 51, 626-629. [CrossRef]

16. Li, H.; Matsuura, M.; Li, W.; Li, Q.; Zhang, Q.; Koike, K. Chemical constituents from the fruits of Sorbus pohuashanensis. Biochem. Syst. Ecol. 2012, 43, 166-168. [CrossRef]

17. Francis, J.K. (Ed.) Wildland Shrubs of the United States and Its Territories: Thamnic Descriptions: Volume 1; Gen. Tech. Rep. IITF-GTR-26; U.S. Department of Agriculture, Forest Service, International Institute of Tropical Forestry: San Juan, PR, USA; U.S. Department of Agriculture, Forest Service, Rocky Mountain Research Station: Fort Collins, CO, USA, 2004; 830p.

18. Olszewska, M. Separation of quercetin, sexangularetin, kaempferol and isorhamnetin for simultaneous HPLC determination of flavonoid aglycones in inflorescences, leaves and fruits of three Sorbus species. J. Pharm. Biomed. Anal. 2008, 48, 629-635. [CrossRef]

19. Gil-Izquierdo, A.; Mellenthin, A. Identification and quantitation of flavonols in rowanberry (Sorbus aucuparia L.) juice. Eur. Food Res. Technol. 2001, 213, 12-17. [CrossRef]

20. Vogl, S.; Picker, P.; Mihaly-Bison, J.; Fakhrudin, N.; Atanasov, A.G.; Heiss, E.H.; Wawrosch, C.; Reznicek, G.; Dirsch, V.M.; Saukel, J.; et al. Ethnopharmacological in vitro studies on Austria's folk medicine-An unexplored lore in vitro anti-inflammatory activities of 71 Austrian traditional herbal drugs. J. Ethnopharmacol. 2013, 149, 750-771. [CrossRef]

21. Räty, M.; Caudullo, G.; de Rigo, D. Sorbus aucuparia in Europe: Distribution, habitat, usage and threats. In European Atlas of Forest Tree Species; San-MiguelAyanz, J., de Rigo, D., Caudullo, G., Houston Durrant, T., Mauri, A., Eds.; Publ. Off. EU: Luxembourg, 2016; pp. 176-177.

22. Plants for A Future. Available online: https://pfaf.org/user/DatabaseSearhResult.aspx (accessed on 23 July 2020).

23. Kalle, R.; Sõukand, R. Historical ethnobotanical review of wild edible plants of Estonia (1770s-1960s). Acta Soc. Bot. Pol. 2012, 81, 271-281. [CrossRef]

24. Broholm, S.L.; Gramsbergen, S.M.; Nyberg, N.T.; Jäger, A.K.; Staerk, D. Potential of Sorbus berry extracts for management of type 2 diabetes: Metabolomics investigation of $1 \mathrm{H}$ NMR spectra, $\alpha$-amylase and $\alpha$-glucosidase inhibitory activities, and in vivo anti-hyperglycaemic activity of $S$. norvegica. J. Ethnopharmacol. 2019, 242. [CrossRef]

25. Kovanda, M.; Challice, J. The genus Micromeles revisited. Folia Geobot. Phytotaxon. 1981, 16, $181-193$. [CrossRef]

26. Cheon, S.M.; Jang, I.; Lee, M.H.; Kim, D.K.; Jeon, H.; Cha, D.S. Sorbus alnifolia protects dopaminergic neurodegeneration in Caenorhabditis elegans. Pharm. Biol. 2017, 55, 481-486. [CrossRef] [PubMed]

27. Aldasoro, J.J.; Aedo, C.; Garmendia, F.M. Revision of Sorbus subgenera Aria and Torminaria (Rosaceae-Maloideae). Syst. Bot. Monogr. 2004, 69, 1-148. [CrossRef]

28. Mrkonjić, Z.O.; Nađpal, J.D.; Beara, I.N.; Sabo, V.S.A.; Četojević-Simin, D.D.; Mimica-Dukić, N.M.; Lesjak, M.M. Phenolic profiling and bioactivities of fresh fruits and jam of Sorbus species. J. Serbian Chem. Soc. 2017, 82, 651-664. [CrossRef]

29. Sulusoglu, M. In vitro pollen viability and pollen germination of service tree (Sorbus domestica L.). Int. J. Biosci. 2014, 5, 108-114. [CrossRef]

30. Majić, B.; Šola, I.; Likić, S.; Cindrić, I.J.; Rusak, G. Characterisation of Sorbus domestica L. bark, fruits and seeds: Nutrient composition and antioxidant activity. Food Technol. Biotechnol. 2015, 53, 463-471. [CrossRef]

31. Hukkanen, A.T.; Pölönen, S.S.; Kärenlampi, S.O.; Kokko, H.I. Antioxidant capacity and phenolic content of sweet rowanberries. J. Agric. Food Chem. 2006, 54, 112-119. [CrossRef] 
32. Sokolov, V.V.; Savel'ev, N.I.; Goncharov, N.P. I. V. Michurin's work on expansion of the plant horticulture assortment and improvement of food quality. Proc. Latv. Acad. Sci. Sect. B Nat. Exact Appl. Sci. 2015, 69, 190-197. [CrossRef]

33. Rengarten, G.A.; Sorokopudov, V.N. Selection of rows as a decorative culture in Russia and in European countries. Vestn. KrasGAU Agron. 2019, 6, 9-15. (In Russian)

34. Mlcek, J.; Rop, O.; Jurikova, T.; Sochor, J.; Fisera, M.; Balla, S.; Baron, M.; Hrabe, J. Bioactive compounds in sweet rowanberry fruits of interspecific rowan crosses. Cent. Eur. J. Biol. 2014, 9, 1078-1086. [CrossRef]

35. Berna, E.; Kampuse, S.; Straumite, E. The suitability of different rowanberry cultivars for production of fruit marmalade. In Proceedings of the Annual 18th International Scientific Conference Research for Rural Development, Jelgava, Latvia, 16-18 May 2012; Treija, S., Skuja, I., Eds.; Latvia University of Agriculture: Jelgava, Latvia, 2012; Volume 1, pp. 109-116.

36. Acuña, U.M.; Atha, D.E.; Ma, J.; Nee, M.H.; Kennelly, E.J. Antioxidant capacities of ten edible North American plants. Phyther. Res. 2002, 16, 63-65. [CrossRef]

37. Olszewska, M.A.; Presler, A.; Michel, P. Profiling of phenolic compounds and antioxidant activity of dry extracts from the selected Sorbus species. Molecules 2012, 17, 3093-3113. [CrossRef] [PubMed]

38. Im, N.K.; Lee, D.S.; Lee, S.R.; Jeong, G.S. Lupeol isolated from Sorbus commixta suppresses $1 \alpha, 25-(\mathrm{OH}) 2 \mathrm{D} 3-$ mediated osteoclast differentiation and bone loss in vitro and in vivo. J. Nat. Prod. 2016, 79, 412-420. [CrossRef] [PubMed]

39. Kim, S.C.; Oh, J.; Subedi, L.; Kim, S.Y.; Choi, S.U.; Kang, R.L. Two new phenolic glycosides from Sorbus commixta. Chem. Pharm. Bull. 2018, 66, 839-842. [CrossRef] [PubMed]

40. Mikulic-Petkovsek, M.; Krska, B.; Kiprovski, B.; Veberic, R. Bioactive components and antioxidant capacity of fruits from nine Sorbus genotypes. J. Food Sci. 2017, 82, 647-658. [CrossRef] [PubMed]

41. Termentzi, A.; Kefalas, P.; Kokkalou, E. LC-DAD-MS (ESI+) analysis of the phenolic content of Sorbus domestica fruits in relation to their maturity stage. Food Chem. 2008, 106, 1234-1245. [CrossRef]

42. Connolly, B.A. $\times$ Sorbaronia fallax (Rosaceae): A new record of an intergeneric hybrid in Connecticut. Rhodora 2009, 111, 123-125. [CrossRef]

43. Pasko, P. South Siberian fruits: Their selected chemical constituents, biological activity, and traditional use in folk medicine and daily nutrition. J. Med. Plants Res. 2012, 6, 4698-4706. [CrossRef]

44. Velebil, J.; Businský, R. Sorbus $\times$ thuringiaca, the correct name for the diploid hybrid between Sorbus aria and S. aucuparia (Rosaceae). Taxon 2016, 65, 352-360. [CrossRef]

45. Termentzi, A.; Alexiou, P.; Demopoulos, V.J.; Kokkalou, E. The aldose reductase inhibitory capacity of Sorbus domestica fruit extracts depends on their phenolic content and may be useful for the control of diabetic complications. Pharmazie 2008, 63, 693-696. [CrossRef]

46. Yang, B.; Ahotupa, M.; Maeaettae, P.; Kallio, H. Composition and antioxidative activities of supercritical $\mathrm{CO}_{2}$-extracted oils from seeds and soft parts of northern berries. Food Res. Int. 2011, 44, 2009-2017. [CrossRef]

47. Klavins, L.; Kviesis, J.; Steinberga, I.; Klavina, L.; Klavins, M. Gas chromatography-mass spectrometry study of lipids in northern berries. Agron. Res. 2016, 14, 1328-1346.

48. Niki, E.; Noguchi, N.; Tsuchihashi, H.; Gotoh, N. Interaction among vitamin C, vitamin E, and $\beta$-carotene. Am. J. Clin. Nutr. 1995, 995, 13225-13265. [CrossRef] [PubMed]

49. B Berna, E.; Kampuse, S. The marmalades of sweet rowanberries as an example of a functional food. In Proceedings of the 7th International Congress of Food Technologists, Biotechnologists and Nutritionists, Opatija, Croatia, 20-23 September 2011; pp. 112-120.

50. Koushik, A.; Hunter, D.J.; Spiegelman, D.; Anderson, K.E.; Buring, J.E.; Freudenheim, J.L.; Goldbohm, R.A.; Hankinson, S.E.; Larsson, S.C.; Leitzmann, M.; et al. Intake of the major carotenoids and the risk of epithelial ovarian cancer in a pooled analysis of 10 cohort studies. Int. J. Cancer 2006, 119, 2148-2154. [CrossRef] [PubMed]

51. Aslantas, R.; Pirlak, L.; Güleryüz, M. The nutritional value of wild fruits from the North eastern Anatolia region of Turkey. Asian J. Chem. 2007, 19, 3072-3078.

52. Ivakhnov, A.D.; Sadkova, K.S.; Sobashnikova, A.S.; Skrebets, T.E. Optimization of oil extraction from rowanberry waste in alcoholic beverage production. Russ. J. Phys. Chem. B 2019, 13, 1135-1138. [CrossRef]

53. Olszewska, M.A.; Nowak, S.; Michel, P.; Banaszczak, P.; Kicel, A. Assessment of the content of phenolics and antioxidant action of inflorescences and leaves of selected species from the genus Sorbus sensu stricto. Molecules 2010, 15, 8769-8783. [CrossRef] 
54. Olszewska, M.A.; Michel, P. Antioxidant activity of inflorescences, leaves and fruits of three Sorbus species in relation to their polyphenolic composition. Nat. Prod. Res. 2009, 23, 1507-1521. [CrossRef]

55. Becerra-Herrera, M.; Lazzoi, M.R.; Sayago, A.; Beltrán, R.; Del Sole, R.; Vasapollo, G. Extraction and determination of phenolic compounds in the berries of Sorbus americana Marsh and Lonicera oblongifolia (Goldie) Hook. Food Anal. Methods 2015, 8, 2554-2559. [CrossRef]

56. Gaivelyte, K.; Jakstas, V.; Razukas, A.; Janulis, V. Variation in the contents of neochlorogenic acid, chlorogenic acid and three quercetin glycosides in leaves and fruits of rowan (Sorbus) species and varieties from collections in Lithuania. Nat. Prod. Commun. 2013, 8, 1105-1110. [CrossRef]

57. Šavikin, K.P.; Zdunić, G.M.; Krstić-Milošević, D.B.; Šircelj, H.J.; Stešević, D.D. Sorbus aucuparia and Sorbus aria as a source of antioxidant phenolics, tocopherols, and pigments. Chem. Biodivers. 2017, 14, 1-11. [CrossRef]

58. Termentzi, A.; Kefalas, P.; Kokkalou, E. Antioxidant activities of various extracts and fractions of Sorbus domestica fruits at different maturity stages. Food Chem. 2006, 98, 599-608. [CrossRef]

59. Bobinaitè, R.; Grootaert, C.; Van Camp, J.; Šarkinas, A.; Liaudanskas, M.; Žvikas, V.; Viškelis, P.; Venskutonis, P.R. Chemical composition, antioxidant, antimicrobial and antiproliferative activities of the extracts isolated from the pomace of rowanberry (Sorbus aucuparia L.). Food Res. Int. 2020, 109310. [CrossRef]

60. Kylli, P.; Nohynek, L.; Puupponen-Pimiä, R.; Westerlund-Wikström, B.; McDougall, G.; Stewart, D.; Heinonen, M. Rowanberry phenolics: Compositional analysis and bioactivities. J. Agric. Food Chem. 2010, 58, 11985-11992. [CrossRef] [PubMed]

61. Ekin, H.N.; Gokbulut, A.; Aydin, Z.U.; Donmez, A.A.; Orhan, I.E. Insight into anticholinesterase and antioxidant potential of thirty-four Rosaceae samples and phenolic characterization of the active extracts by HPLC. Ind. Crops Prod. 2016, 91, 104-113. [CrossRef]

62. Kim, M.B.; Park, J.S.; Lim, S. Bin Antioxidant activity and cell toxicity of pressurised liquid extracts from 20 selected plant species in Jeju, Korea. Food Chem. 2010, 122, 546-552. [CrossRef]

63. Rutkowska, M.; Olszewska, M.A.; Kolodziejczyk-Czepas, J.; Nowak, P.; Owczarek, A. Sorbus domestica leaf extracts and their activity markers: Antioxidant potential and synergy effects in scavenging assays of multiple oxidants. Molecules 2019, 24, 2289. [CrossRef]

64. Isaikina, N.V.; Kalinkina, G.I.; Razina, T.G.; Zueva, E.P.; Rybalkina, O.Y.; Ulirich, A.V.; Fedorova, E.P.; Shilova, A.B. Sorbus aucuparia L. fruit is a source of the drug for increasing the efficiency of tumor chemotherapy. Russ. J. Bioorg. Chem. 2018, 44, 899-905. [CrossRef]

65. Olszewska, M.A.; Michel, P. Activity-guided isolation and identification of free radical-scavenging components from various leaf extracts of Sorbus aria (L.) Crantz. Nat. Prod. Res. 2012, 26, 243-254. [CrossRef]

66. Denev, P.; Kratchanova, M.; Ciz, M.; Lojek, A.; Vasicek, O.; Nedelcheva, P.; Blazheva, D.; Toshkova, R.; Gardeva, E.; Yossifova, L.; et al. Biological activities of selected polyphenol-rich fruits related to immunity and gastrointestinal health. Food Chem. 2014, 157, 37-44. [CrossRef]

67. Gu, H.; Chen, F.; Zhang, Q.; Zang, J. Application of ionic liquids in vacuum microwave-assisted extraction followed by macroporous resin isolation of three flavonoids rutin, hyperoside and hesperidin from Sorbus tianschanica leaves. J. Chromatogr. B Anal. Technol. Biomed. Life Sci. 2016, 1014, 45-55. [CrossRef]

68. Yoo, J.-H.; Doh, E.-S.; Chang, J.-P.; Kil, K.-J. Antioxidant activities of hot water and ethanol extracts from the stem of Sorbus commixta Heal. Korea J. Herbol. 2017, 32, 29-36. [CrossRef]

69. Bae, J.-T.; Sim, G.-S.; Kim, J.-H.; Pyo, H.-B.; Yun, J.-W.; Lee, B.-C. Antioxidative activity of the hydrolytic enzyme treated Sorbus commixta Hedl. and its inhibitory effect on matrix metalloproteinase-1 in UV irradiated human dermal fibroblasts. Arch. Pharm. Res. 2007, 30, 1116-1123. [CrossRef] [PubMed]

70. Yoshizawa, Y.; Kawaii, S.; Urashima, M.; Fukase, T.; Sato, T.; Murofushi, N.; Nishimura, H. Differentiation-inducing effects of small fruit juices on HL-60 leukemic cells. J. Agric. Food Chem. 2000, 48, 3177-3182. [CrossRef] [PubMed]

71. Raudone, L.; Raudonis, R.; Gaivelyte, K.; Pukalskas, A.; Viškelis, P.; Venskutonis, P.R.; Janulis, V. Phytochemical and antioxidant profiles of leaves from different Sorbus L. species. Nat. Prod. Res. 2015, 29, 281-285. [CrossRef] [PubMed] 
72. Rutkowska, M.; Owczarek, A.; Kolodziejczyk-Czepas, J.; Michel, P.; Piotrowska, D.G.; Kapusta, P.; Nowak, P.; Olszewska, M.A. Identification of bioactivity markers of Sorbus domestica leaves in chromatographic, spectroscopic and biological capacity tests: Application for the quality control. Phytochem. Lett. 2019, 30, 278-287. [CrossRef]

73. Ullah, H.; Wilfred, C.D.; Shaharun, M.S. Ionic liquid-based extraction and separation trends of bioactive compounds from plant biomass. Sep. Sci. Technol. 2019, 54, 559-579. [CrossRef]

74. Guerrero-Analco, J.A.; Martineau, L.; Saleem, A.; Madiraju, P.; Muhammad, A.; Durst, T.; Haddad, P.; Arnason, J.T. Bioassay-guided isolation of the antidiabetic principle from Sorbus decora (Rosaceae) used traditionally by the Eeyou Istchee Cree First Nations. J. Nat. Prod. 2010, 73, 1519-1523. [CrossRef]

75. Magnus, S.; Gazdik, F.; Anjum, N.A.; Kadlecova, E.; Lackova, Z.; Cernei, N.; Brtnicky, M.; Kynicky, J.; Klejdus, B.; Necas, T.; et al. Assessment of antioxidants in selected plant rootstocks. Antioxidants 2020, 9, 209. [CrossRef]

76. Kähkönen, M.P.; Hopia, A.I.; Heinonen, M. Berry phenolics and their antioxidant activity. J. Agric. Food Chem. 2001, 49, 4076-4082. [CrossRef]

77. Saftner, R.; Polashock, J.; Ehlenfeldt, M.; Vinyard, B. Biochemical composition and antiradical activity of rowanberry (Sorbus L.) cultivars and hybrids with different Rosaceae L. cultivars. Eur. J. Hortic. Sci. 2009, 59, 195-201.

78. Baltacioğlu, C.; Velioğlu, S.; Karacabey, E. Changes in total phenolic and flavonoid contents of rowanberry fruit during postharvest storage. J. Food Qual. 2011, 34, 278-283. [CrossRef]

79. Raspé, O.; Findlay, C.; Jacquemart, A.L. Sorbus aucuparia L. J. Ecol. 2000, 88, 910-930. [CrossRef]

80. EFSA. Opinion of the scientific panel on contaminants in the food chain on a request from the Commission related to cyanogenic compounds as undesirable substances in animal feed. EFSA J. 2007, 434, 1-67.

81. Aladedunye, F.; Matthäus, B. Phenolic extracts from Sorbus aucuparia (L.) and Malus baccata (L.) berries: Antioxidant activity and performance in rapeseed oil during frying and storage. Food Chem. 2014, 159, 273-281. [CrossRef]

82. Vlavcheski, F.; Young, M.; Tsiani, E. Antidiabetic effects of hydroxytyrosol: In vitro and in vivo evidence. Antioxidants 2019, 8, 188. [CrossRef]

83. Zymone, K.; Raudone, L.; Raudonis, R.; Marksa, M.; Ivanauskas, L.; Janulis, V. Phytochemical profiling of fruit powders of twenty Sorbus L. Cultivars. Molecules 2018, 23, 2593. [CrossRef]

84. Yu, T.; Lee, Y.J.; Jang, H.J.; Kim, A.R.; Hong, S.; Kim, T.W.; Kim, M.Y.; Lee, J.; Lee, Y.G.; Cho, J.Y. Anti-inflammatory activity of Sorbus commixta water extract and its molecular inhibitory mechanism. J. Ethnopharmacol. 2011, 134, 493-500. [CrossRef]

85. Takó, M.; Kerekes, E.B.; Zambrano, C.; Kotogán, A.; Papp, T.; Krisch, J.; Vágvölgyi, C. Plant phenolics and phenolic-enriched extracts as antimicrobial agents against food-contaminating microorganisms. Antioxidants 2020, 9, 165. [CrossRef]

86. Rodríguez-García, C.; Sánchez-Quesada, C.; Gaforio, J.J.; Gaforio, J.J. Dietary flavonoids as cancer chemopreventive agents: An updated review of human studies. Antioxidants 2019, 8, 137. [CrossRef]

87. Kristo, A.S.; Klimis-Zacas, D.; Sikalidis, A.K. Protective role of dietary berries in cancer. Antioxidants 2016, 5, 37. [CrossRef]

88. Razina, T.G.; Zueva, E.P.; Ulrich, A.V.; Rybalkina, O.Y.; Chaikovskii, A.V.; Isaikina, N.V.; Kalinkina, G.I.; Zhdanov, V.V.; Zyuz'kov, G.N. Antitumor effects of Sorbus aucuparia L. extract highly saturated with anthocyans and their mechanisms. Bull. Exp. Biol. Med. 2016, 162, 93-97. [CrossRef] [PubMed]

89. Deligiannidou, G.E.; Papadopoulos, R.E.; Kontogiorgis, C.; Detsi, A.; Bezirtzoglou, E.; Constantinides, T. Unraveling natural products' role in osteoarthritis management-An overview. Antioxidants 2020, 9, 348. [CrossRef] [PubMed]

90. Varela-López, A.; Bullón, P.; Giampieri, F.; Quiles, J.L. Non-nutrient, naturally occurring phenolic compounds with antioxidant activity for the prevention and treatment of periodontal diseases. Antioxidants 2015, 4, 447-481. [CrossRef] [PubMed]

91. Magrone, T.; Magrone, M.; Russo, M.A.; Jirillo, E. Recent advances on the anti-inflammatory and antioxidant properties of red grape polyphenols: In vitro and in vivo studies. Antioxidants 2020, 9, 35. [CrossRef] [PubMed]

92. Grodzicki, W.; Dziendzikowska, K. The role of selected bioactive compounds in the prevention of Alzheimer's disease. Antioxidants 2020, 9, 229. [CrossRef] 
93. Laube, M.; Kniess, T.; Pietzsch, J. Development of antioxidant COX-2 inhibitors as radioprotective agents for radiation therapy-A hypothesis-driven review. Antioxidants 2016, 5, 14. [CrossRef]

94. Bernini, R.; Carastro, I.; Palmini, G.; Tanini, A.; Zonefrati, R.; Pinelli, P.; Brandi, M.L.; Romani, A. Lipophilization of hydroxytyrosol-enriched fractions from Olea europaea L. byproducts and evaluation of the in vitro effects on a model of colorectal cancer cells. J. Agric. Food Chem. 2017, 65, 6506-6512. [CrossRef] [PubMed]

95. Aladedunye, F.; Niehaus, K.; Bednarz, H.; Thiyam-Hollander, U.; Fehling, E.; Matthäus, B. Enzymatic lipophilization of phenolic extract from rowanberry (Sorbus aucuparia) and evaluation of antioxidative activity in edible oil. LWT Food Sci. Technol. 2015, 60, 56-62. [CrossRef]

96. Zhong, Y.; Shahidi, F. Lipophilized epigallocatechin gallate (EGCG) derivatives as novel antioxidants. J. Agric. Food Chem. 2011, 59, 6526-6533. [CrossRef]

97. Bobinaitè, R.; Kraujalis, P.; Tamkutè, L.; Urbonavičienè, D.; Viškelis, P.; Venskutonis, P.R. Recovery of bioactive substances from rowanberry pomace by consecutive extraction with supercritical carbon dioxide and pressurized solvents. J. Ind. Eng. Chem. 2020, 85, 152-160. [CrossRef]

98. Clifford, M.N.; Kerimi, A.; Williamson, G. Bioavailability and metabolism of chlorogenic acids (acyl-quinic acids) in humans. Compr. Rev. Food Sci. Food Saf. 2020, 1-54. [CrossRef]

99. Kim, T.H. Chlorogenic acid isomers from Sorbus commixta of ulleung island origin and their inhibitory effects against advanced glycation end product (AGE) formation and radical scavenging activity. J. Korean Soc. Food Sci. Nutr. 2016, 45, 1208-1213. [CrossRef]

100. Boath, A.S.; Stewart, D.; McDougall, G.J. Berry components inhibit $\alpha$-glucosidase in vitro: Synergies between acarbose and polyphenols from black currant and rowanberry. Food Chem. 2012, 135, 929-936. [CrossRef] [PubMed]

101. Küpeli Akkol, E.; Gürağaç Dereli, F.T.; Taştan, H.; Sobarzo-Sánchez, E.; Khan, H. Effect of Sorbus domestica and its active constituents in an experimental model of colitis rats induced by acetic acid. J. Ethnopharmacol. 2020, 251. [CrossRef] [PubMed]

102. Lee, T.K.; Roh, H.S.; Yu, J.S.; Kwon, D.J.; Kim, S.Y.; Baek, K.H.; Kim, K.H. A novel cytotoxic activity of the fruit of Sorbus commixta against human lung cancer cells and isolation of the major constituents. J. Funct. Foods 2017, 30, 1-7. [CrossRef]

103. Kim, M.S.; Sohn, H.Y. Anti-coagulation and anti-platelet aggregation activity of the mature fruit of Sorbus commixta. Korean J. Microbiol. Biotechnol. 2015, 43, 373-377. [CrossRef]

104. Kavak, D.D.; Akdeniz, B. Sorbus umbellata (Desf.) Fritsch var. umbellata leaves: Optimization of extraction conditions and investigation antimicrobial, cytotoxic, and $\beta$-glucuronidase inhibitory potential. Plant Foods Hum. Nutr. 2019, 74, 364-369. [CrossRef]

105. Choi, H.J. In vitro antiviral activity of sakuranetin against human rhinovirus 3. Osong Public Heal. Res. Perspect. 2017, 8, 415-420. [CrossRef]

106. Kim, M.J.; Jung, T.K.; Kim, M.-H.; Yoon, K.-S. In vitro screening of Jeju island plants for cosmetic ingredients. KSBB J. 2018, 33, 76-82. [CrossRef]

(C) 2020 by the authors. Licensee MDPI, Basel, Switzerland. This article is an open access article distributed under the terms and conditions of the Creative Commons Attribution (CC BY) license (http://creativecommons.org/licenses/by/4.0/). 